\title{
Seismological and Engineering Characteristics of Strong Motion Data from 24 and 26 September 2019 Marmara Sea Earthquakes
}

\section{Fatma Sevil Malcıoğlu ( $\sim$ sevil.malcioglu@boun.edu.tr)}

Bogazici University Kandilli Observatory and Research Institute https://orcid.org/0000-0001-6065-4768 Hakan Süleyman

Boğaziçi University Kandilli Observatory and Earthquake Research Institute Eser Çaktı

Bogazici University Kandilli Observatory and Earthquake Research Institute

\section{Research Article}

Keywords: Earthquake ground motions, Seismic attenuation, Ground motion prediction equations, Ground motion duration, North Anatolian fault, Marmara.

Posted Date: September 24th, 2021

DOI: https://doi.org/10.21203/rs.3.rs-919523/v1

License: (a) (1) This work is licensed under a Creative Commons Attribution 4.0 International License. Read Full License 


\title{
Seismological and Engineering Characteristics of Strong Motion Data from 24 and 26 September 2019 Marmara Sea Earthquakes
}

\author{
Fatma S. Malcıoğlu' ${ }^{1}$, Hakan Süleyman ${ }^{1}$, Eser Çaktı ${ }^{1}$ \\ ${ }^{1}$ Department of Earthquake Engineering, Kandilli Observatory And Earthquake Research Institute, Boğaziçi \\ University, 34684, Çengelköy, Istanbul, Turkey. E-mail: sevil.malcioglu@boun.edu.tr
}

\begin{abstract}
An $M_{W} 4.5$ earthquake took place on September 24, 2019 in the Marmara Sea. Two days after, on September 26, 2019, Marmara region was rattled by an $M_{w} 5.7$ earthquake. With the intention of compiling an ample strong ground motion data set of recordings, we have utilized the stations of Istanbul Earthquake Rapid Response and Early Warning System operated by the Department of Earthquake Engineering of Boğaziçi University and of the National Strong Motion Network operated by AFAD. All together 438 individual records are used to calculate the source parameters of events; namely, corner frequency, radius, rupture area, average source dislocation, source duration and stress drop. Some of these parameters are compared with empirical relationships and discussed extensively. Duration characteristics are analyzed in two steps; first, by making use of the time difference between P-wave and S-wave onsets and then, by considering S-wave durations and significant durations. It is observed that they yield similar trends with global models. PGA, PGV and SA values are compared with three commonly used ground motion prediction models. At distances closer than about $60 \mathrm{~km}$ observed intensity measures mostly conform with the GMPE predictions. Beyond $60 \mathrm{~km}$ their attenuation is clearly faster than those of GMPEs. Frequency-dependent Q models are developed for both events. Their consistency with existing regional models are confirmed.
\end{abstract}

Keywords: Earthquake ground motions; Seismic attenuation; Ground motion prediction equations; Ground motion duration; North Anatolian fault; Marmara.

\section{Introduction}

Istanbul was hit by a moderate size earthquake of $\mathrm{M}_{\mathrm{w}} 5.7$ on September 26, 2019, which was preceded by a $M_{W} 4.5$ event approximately two days earlier. It was the largest earthquake that took place on the central Marmara segment of the North Anatolian Fault (NAF) in recent years. The earthquake was widely felt across Istanbul and caused structural damage in private and 
public buildings. Mobile communication was lost for about two hours. It has stirred many public and administrative discussions and evaluations, and re-ignited the long-standing question of whether a destructive earthquake with a larger magnitude will occur in the near future. In the past, two destructive earthquakes that occurred on the NAF, immediately east of Istanbul ( $M_{W} 7.4$ in August 1999 and $M_{W} 7.2$ in November 1999), caused thousands of deaths along with excessive structural damage. It is crucial to advance the existing knowledge in understanding the potential hazard and risk that a major earthquake may cause in this region. Existing strong ground motion networks in Istanbul are rich sources of seismological information for studying the past and future potential earthquakes in this region.

In this study, we focus on estimating seismological and engineering parameters of these two events. Seismic activity on the segments of the NAF to the south of Istanbul has been significantly low. Between 1999 and 2020, there were only nine earthquakes with magnitudes 4.5 and above that could be associated with the central Marmara and Princes' Islands segments (KOERI-RETMC 2020). We used recordings from the strong motion stations in and around Istanbul. We estimated the following source parameters: corner frequency, source duration, source radius, rupture area, average source dislocation and stress drop. We have examined the regional distance dependence of the duration between P-wave and S-wave arrivals. Then, we have studied possible correlations between the hand-picked S-wave durations with hypocentral distance. The significant duration models have been prepared for 5\%-75\% and 5\%-95\% cases separately and the results are compared with the global models. Next, ground motion parameters (PGAs, PGVs, SAs at various periods) have been calculated and a discussion on engineering parameters has been presented. They have been compared with three commonly used ground motion prediction equations (GMPEs) for the region. In the last part of the paper, we have discussed the validity of frequency-dependent anelastic attenuation models developed by comparing them with global and regional models proposed in the literature.

\section{Earthquake Information}

An earthquake measuring 4.5 on moment magnitude scale was detected off the coast of Silivri (Sea of Marmara, northwestern Turkey) on 24th of September at 11:00:21 local time. Two days later, another earthquake with a moment magnitude of 5.7 struck the same region. Brief information on both earthquakes is summarized in Table 1. Their depths are estimated as 9.9 $\mathrm{km}$ and $13.3 \mathrm{~km}$, respectively, by Kandilli Observatory and Earthquake Research Institute (KOERI) (KOERI-RETMC 2019a \& 2019b). The Ministry of Interior's Disaster and Emergency Management Presidency (AFAD) reported slightly larger moment magnitudes and smaller depths than KOERI for both events (AFAD 2020). Moreover, the United States Geological Survey (USGS) and European Mediterranean Seismological Centre (EMSC) developed similar body wave 
selected stations and the epicentral distances of closest and furthest recordings are summarized in Table 2.

Table 2 Selected stations and their minimum and maximum epicentral distances

\begin{tabular}{|c|c|c|c|c|}
\hline & \multicolumn{2}{|c|}{ IERREWS } & \multicolumn{2}{|c|}{ AFAD } \\
\hline & $\mathrm{M}_{\mathrm{w}}=4.5$ & $\mathrm{M}_{\mathrm{w}}=5.7$ & $\mathrm{M}_{\mathrm{w}}=4.5$ & $\mathrm{M}_{\mathrm{w}}=5.7$ \\
\hline Number of Stations & 56 & 56 & 14 & 20 \\
\hline Minimum Epicentral Distance, $\mathrm{R}_{\mathrm{ep}, \min }(\mathrm{km})$ & $\sim 23$ & $\sim 23$ & $\sim 21$ & $\sim 22$ \\
\hline Maximum Epicentral Distance, $R_{\text {epi, } \max }(\mathrm{km})$ & $\sim 100$ & 100 & ح9 & $\sim 100$ \\
\hline
\end{tabular}

A total of 70 and 76 stations located in and around Istanbul were selected to analyse the $\mathrm{M}_{\mathrm{W}} 4.5$ and $\mathrm{M}_{\mathrm{W}} 5.7$ earthquakes, respectively. The spatial distribution of selected stations and earthquakes' epicentres including their focal mechanism solutions are illustrated in Figure 1.

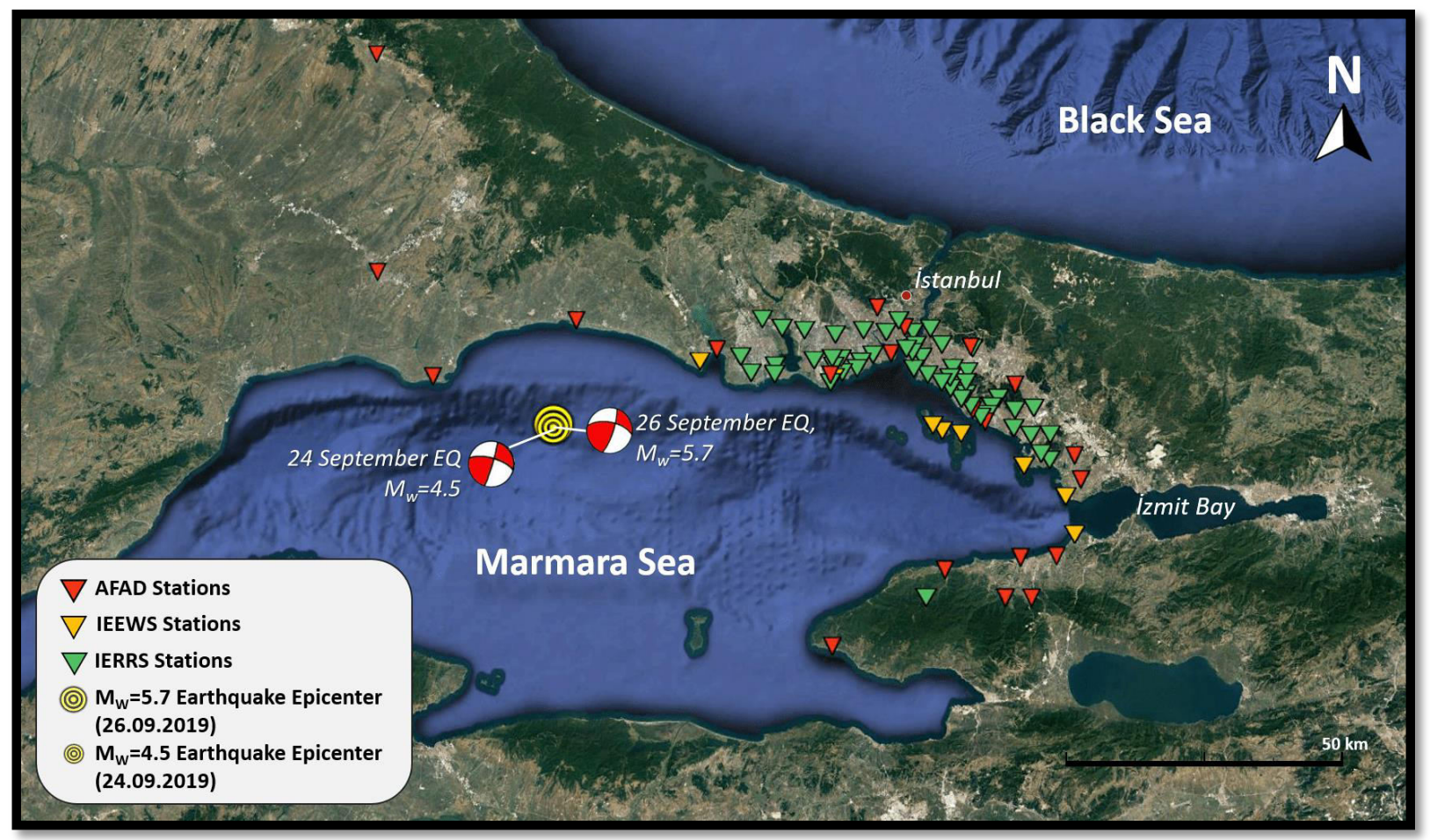

Fig. 1 Epicentres of the $24^{\text {th }} \& 26^{\text {th }}$ September 2019 earthquakes and spatial distribution of selected stations (Focal mechanisms are taken from Karabulut et al. (2021)).

\section{Data Processing}

All selected recordings are processed and analysed individually. Firstly, to provide physically meaningful velocities and displacements, all raw acceleration time histories are uniformly detrended. P-wave arrivals, S-wave windows and noise windows are hand-picked following Kishida et al. (2016) as shown in Figure 2. The majority of recordings are sufficiently long 
enough to select the pre-event noise window, similar to the length of the hand-picked S-wave window. Fourier spectra of S-wave and noise windows are estimated to check the signal-to noise ratios. S-wave and three times noise spectra are excessively smoothed and checked for any intersections between them. The frequencies of intersection points (if they exist, most of the time the signal is way above the noise level) are used as the low-pass corner of the filters. It has been noted that the recordings in the database are mostly of high quality with low noise levels and a wide usable frequency band - reaching up to $50 \mathrm{~Hz}$.
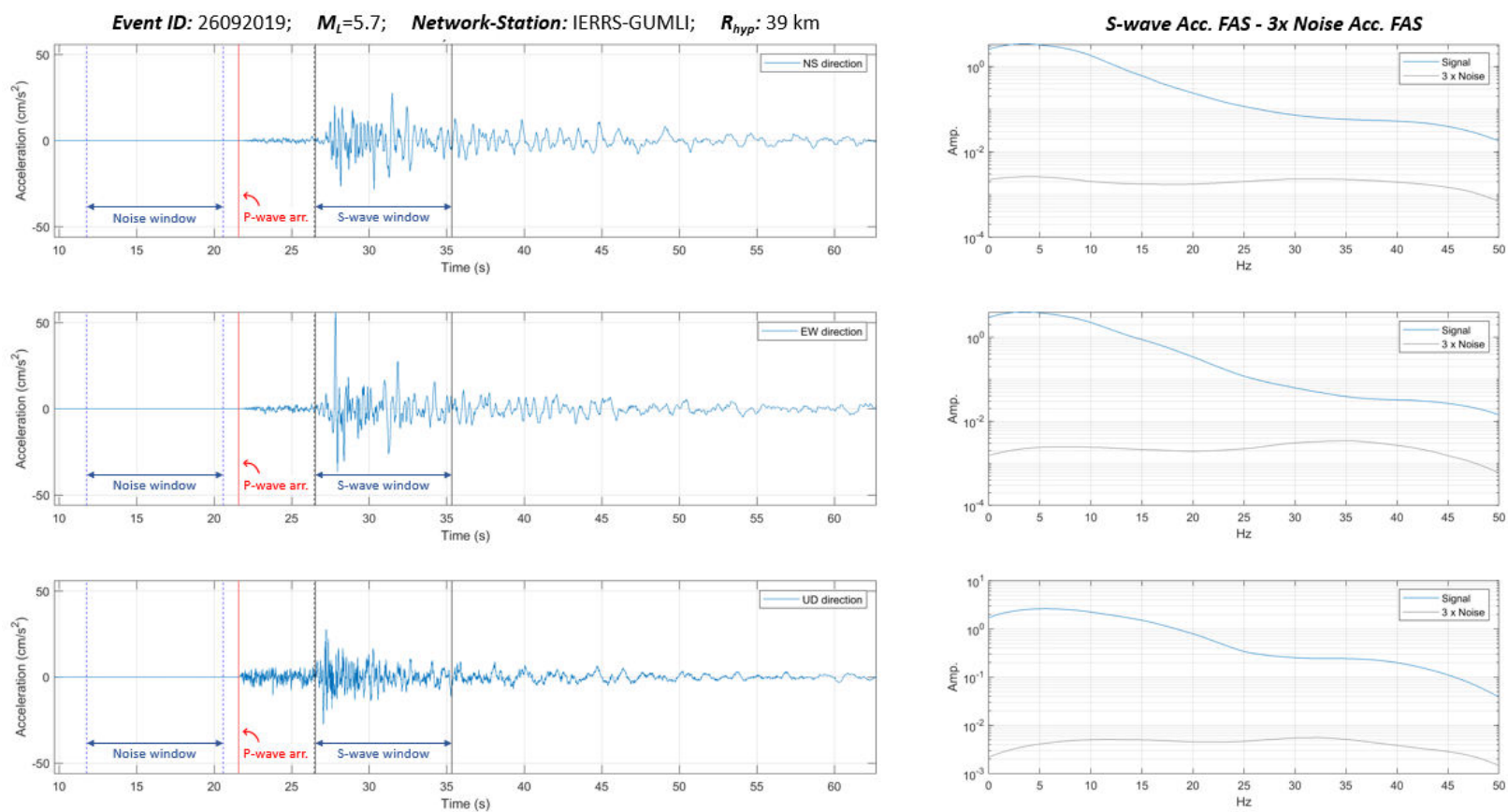

Fig. 2 Sample MATLAB screenshot of the process for hand-picking P-wave arrivals, S-wave windows and noise windows from each recording individually (left); followed by an automated Fourier transform of S-wave and tripled noise spectra to observe effects of noise on S-wave spectrum (right).

Each acceleration trace is examined one by one and individual high-pass corner frequencies are determined for each recording separately via visual inspection of the velocity and displacement waveforms. As the final step of data preparation, band-pass filtering is applied to the recordings using the individually selected low-pass and high-pass filter limits in order to eliminate the noise contamination. However, for computation of engineering parameters (PGA, PGV and SA values), low-pass filter frequency limit is kept constant at $20 \mathrm{~Hz}$, in order to obtain comparable information for the short period range of the response spectrum by considering the total duration of the time histories. 


\section{Source Parameters}

The corner frequency of the source model is calculated using equation 1, introduced by Andrews (1986). This equation is selected due to the equation's objectivity in calculating the corner frequency:

$$
f_{c}=\frac{1}{2 \pi} \sqrt{\frac{\int_{0}^{\infty} V^{2}(f) d f}{\int_{0}^{\infty} D^{2}(f) d f}}
$$

where $V(f)$ and $D(f)$ are the Fourier amplitude spectra of velocity and displacement, respectively. For this estimation, we made use of only the usable frequency ranges of S-wave spectra -those having very high usable bandwidths. All individual $f_{c}$ calculations are averaged over all components to obtain the corner frequencies of these events.

The source radii of the seismic sources are estimated through Brune's model (1970) as,

$$
r=\frac{0.37 \beta}{f_{c}}
$$

where, $\beta$ is the crustal shear wave velocity in $\mathrm{km} / \mathrm{s}$. The crustal shear wave velocity of the Marmara region is taken as $3.42 \mathrm{~km} / \mathrm{s}$ (RETMC, personal communication 2018). Once the radii are known, a circular rupture plane area can be estimated with the following equation:

$$
A=\pi r^{2}
$$

The seismic moment $\left(\mathrm{M}_{0}\right)$ of the $\mathrm{M}_{\mathrm{W}} 4.5$ event is reported as $6.494+15 \mathrm{Nm}$ by KOERI-RETMC (2019a). The conversion from $M_{w}$ to $M_{0}$ for $M_{w} 5.7$ event is applied by inverting the well-known relationship as defined by Hanks and Kanamori (1979),

$$
M_{W}=\frac{2}{3} \log _{10} M_{0}-10.7 \rightarrow M_{0}=10^{\left(M_{w}+10.7\right) \frac{3}{2}}
$$

The shear modulus can be calculated by using the equation of $\mu=\beta^{2} \rho$. Assuming the density of earth crust as $\rho=2.7 \mathrm{~g} / \mathrm{cm}^{2}$, the shear modulus is calculated as $\mu=3.16 \mathrm{e}+10 \mathrm{~Pa}$. Thus, from the equation of scalar seismic moment, the average source dislocation, $\bar{D}$, can simply be estimated by formulating the seismic moment equation as,

$$
M_{0}=\mu \bar{D} A \rightarrow \bar{D}=\frac{M_{0}}{\mu A}
$$

Several source duration models are proposed in the past (Boatwright and Choy 1992; Hanks and McGuire 1981; Beresnev 2002). All of these models assume that source duration is inversely proportional to $f_{c}$, while many of them use different coefficients in their formulations. The approximation presented in Boatwright and Choy (1992) and in Boore (1983) is used in this study, 


$$
D_{s}=\frac{1}{f_{c}}
$$

The static stress drop, $\Delta \sigma$, is the difference in shear stress on the fault plane before and after the earthquake. Based on Eshelby (1957) and Keilis-Borok (1959), the following relationship holds for a circular fault rupture with a homogeneous stress drop:

$$
\Delta \sigma=\frac{7 M_{0}}{16 r^{3}}
$$

The unit of stress drop in this equation is in Pascal $\left(\mathrm{Pa}=10^{-5} \mathrm{bar}\right)$.

The results obtained for the $\mathrm{M}_{\mathrm{W}} 4.5$ and $\mathrm{M}_{\mathrm{W}} 5.7$ earthquakes regarding the source parameters are listed in Table 3.

\begin{tabular}{|c|c|c|}
\hline & $\mathrm{M}_{\mathrm{W}}=4.5$ & $\mathrm{M}_{\mathrm{w}}=5.7$ \\
\hline$M_{0}(N m)$ & $6.494 \mathrm{e}+15^{*}$ & $3.98 \mathrm{E}+17$ \\
\hline $\boldsymbol{f}_{C}(\boldsymbol{H z})$ & $0.8( \pm 0.34)$ & $0.59( \pm 0.3)$ \\
\hline$r(k m)$ & 1.58 & 2.15 \\
\hline$A\left(k m^{2}\right)$ & 7.84 & 14.52 \\
\hline$A_{W C 1994}\left(\mathrm{~km}^{2}\right)$ & 4.3 & 41.7 \\
\hline$A_{T 2017}\left(k^{2}\right)$ & 5.7 & 61.6 \\
\hline $\bar{D}(m)$ & 0.03 & 0.75 \\
\hline $\bar{D}_{T 2017}(m)$ & 0.03 & 0.12 \\
\hline$D_{S}(s)$ & 1.25 & 1.69 \\
\hline$\Delta \sigma($ bars $)$ & 7.2 & 175.2 \\
\hline
\end{tabular}

Table 3 Estimated source parameters.

Approximated rupture areas (A) are calculated and also with empirical source scaling relationships developed by Wells and Coppersmith (1994) and Thingbaijam et al. (2017), referred as WC1994 and T2017, respectively, in Table 3. Rupture areas calculated through these relationships for the $\mathrm{M}_{\mathrm{W}} 4.5$ event are slightly underestimated, while those for $\mathrm{M}_{\mathrm{W}}=5.7$ are significantly different than the ones presented in Table 3.

Our estimation of $0.75 \mathrm{~m}$ as the average source dislocation of the $\mathrm{M}_{\mathrm{w}} 5.7$ event is larger and in good agreement with the slip range considered in Figure 7 of Karabulut et al. (2021). Average source dislocations calculated through Thingbaijam et al. (2017) are shown in Table 3 as well. 
The calculated stress drop value of 175.2 bar for the $\mathrm{M}_{\mathrm{W}} 5.7$ event is exceptionally high when compared with stress drop estimations globally. Nevertheless, some rare very high values are observed in some strike-slip and thrust faults, as well as in shallow earthquakes in the past (Allmann and Shearer 2009). We checked the consistency of this value with a $\Delta \sigma$ model suitable for elliptic ruptures. For an elliptic rupture, we assume the major-axis, denoted as a, ranging from 3.2 to $4.2 \mathrm{~km}$ and the minor-axis, denoted as $b$, ranging from 1.1 to $1.5 \mathrm{~km}$ - each $a$ and $b$ combination resulting in approximately the same area to that calculated by assuming a circular rupture (Table 3). We calculated $\Delta \sigma$ by using the equation B12 in Denolle and Shearer (2016), arranged for elliptic slip distribution based on Aki (1972):

$$
\Delta \sigma=C \times \frac{M_{0}}{\pi a b^{2}}
$$

where $C=16 /\left(3 \pi^{3 / 2}\right) \sim 0.95$. For a set of axes combinations mentioned above, we obtain $\Delta \sigma$ values ranging from 167.2 to 236.9 bar. The $\Delta \sigma$ estimated for a circular rupture (175.2 bar), falls within this range - showing consistency between the results.

\section{Duration of Strong Ground Motions}

\subsection{Duration between $P$-wave and $S$-wave arrivals}

The first part of this section deals with the duration between hand-picked P-wave and S-wave onsets. These durations are observed in each recording individually. The P-wave and S-wave onsets are selected by plotting three components one under other simultaneously for a single visual selection. The distribution of the durations between P-wave and S-wave onsets in Figure 3. shows very high linearity, which yields a regression coefficient of $\mathrm{R}^{2}=99 \%$. The intersection of the fitted model is at 0.34 seconds. Due to its insignificant weight in the equation, it can be ignored and only the path contribution can be considered as:

$$
D_{P-\text { wave arrival-s-wave arrival }}=0.118 \times R_{\text {hyp }}
$$

It can be said that the estimated linear model is in good agreement with the global linear model that is $\mathrm{R}_{\text {hyp }} / 8$, used in previous studies (Ancheta et al. 2013; Kishida et al. 2016). 


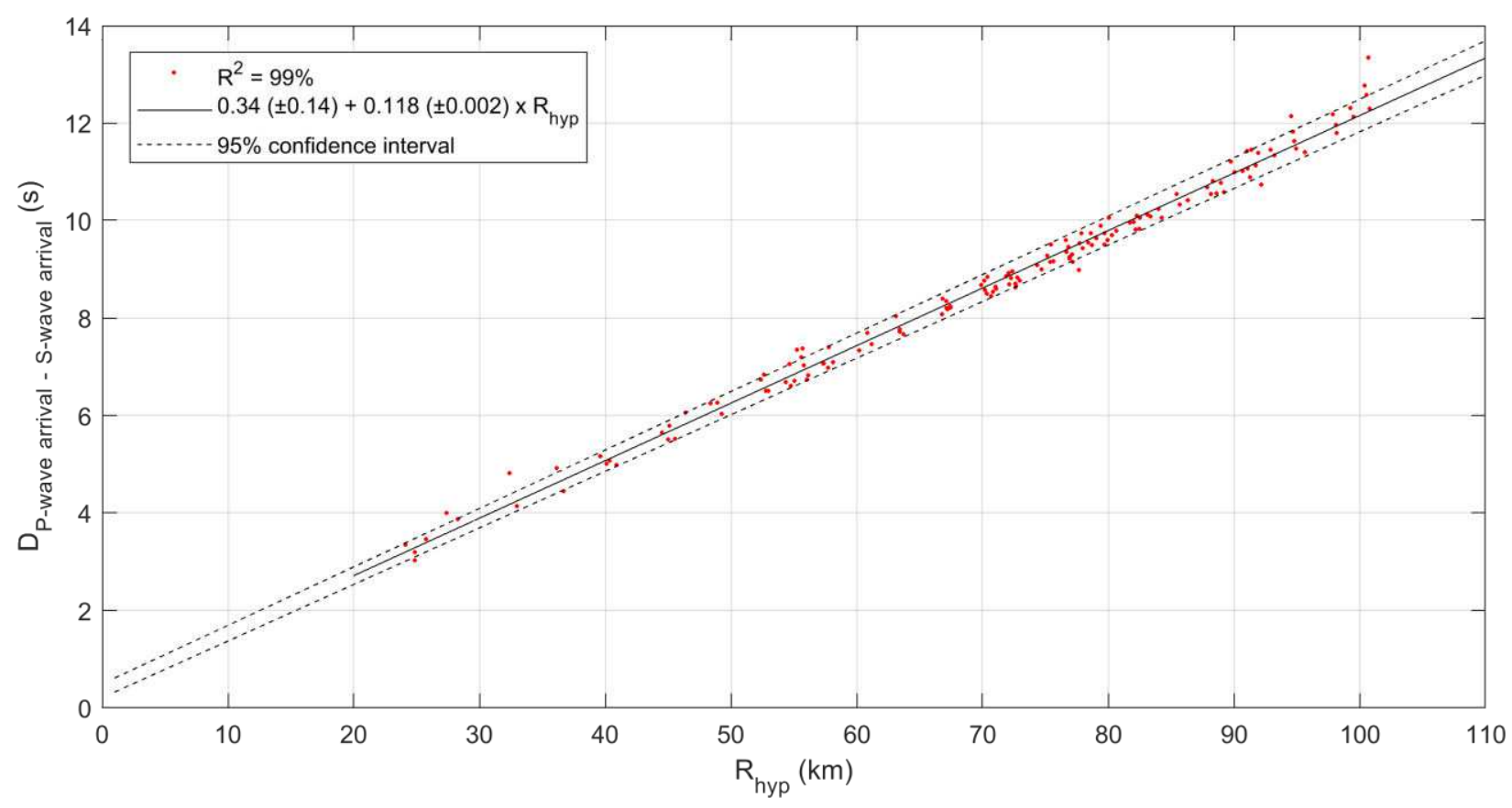

Fig. 3 Duration between hand-picked P-wave and S-wave arrivals versus hypocentral distance of both events; the solid line is a first-degree polynomial fitting, while the dashed lines represent the $95 \%$ confidence intervals; the fitting equation is shown in the legend with $\pm 95 \%$ confidence intervals.

\subsection{Duration of $S$-waves}

Duration of strong shaking defined through various methods is considered as the combinations between source, path and site contributions (Kempton and Stewart 2006; Bommer et al. 2009; Ghofrani and Atkinson 2015). In this study, we only focus on the source and path contributions. Therefore, durations of hand-picked S-wave windows are discussed in terms of their source and path components as,

$$
\mathrm{D}_{\text {S-wave }}=\mathrm{D}_{\text {source }}+\mathrm{D}_{\text {path }}=\mathrm{D}_{\text {source }}+c_{\text {path }} \times \mathrm{R}_{\text {hyp }}
$$

where the S-wave duration is modelled as the sum of source and path durations. Estimations of individual S-wave durations of each recording for the two events are plotted against hypocentral distance in Figure 4. The S-wave durations are estimated for two horizontal components separately. The data are slightly scattered because of the subjectivity in the selection of the end of the S-wave windows, returning $\mathrm{R}^{2}=49 \%$ for the $\mathrm{M}_{\mathrm{W}} 5.7$ event and $\mathrm{R}^{2}=46 \%$ for the $\mathrm{M}_{\mathrm{W}} 4.5$ event. Corresponding relationships for the two events can be given as,

$$
\begin{array}{ll}
4.10( \pm 1.56)+0.08( \pm 0.02) \times R_{h y p} & \left(M_{W}=4.5\right) \\
2.37( \pm 2.23)+0.13( \pm 0.03) \times R_{h y p} & \left(M_{W}=5.7\right)
\end{array}
$$

where the values in parentheses show the $\pm 95 \%$ confidence intervals. The intercepts of linear fittings are associated with source durations, while the coefficients 0.08 and 0.13 are related to path contribution. In the previous section, theoretical source durations are estimated as $1.25 \mathrm{~s}$ 
for the $M_{W} 4.5$ and $1.59 \mathrm{~s}$ for the $\mathrm{M}_{\mathrm{W}} 5.7$ event. Despite the fact that a longer source duration is estimated for the larger event through the empirical relationship, the fitted models over the observed data return a shorter source duration for the larger event. The observed source durations are 4.10 ( \pm 1.56) for $\mathrm{M}_{\mathrm{W}} 4.5$ and 2.37 ( \pm 2.23 ) for $\mathrm{M}_{\mathrm{W}} 5.7$ event. It can be said that the calculated and observed source duration values of $\mathrm{M}_{\mathrm{W}} 5.7$ event are in close agreement. However, the observed source duration of the $\mathrm{M}_{\mathrm{W}} 4.5$ earthquake is significantly higher than the calculated one. It should be noted that as the S-wave windows are handpicked, the S-wave duration models involve a certain amount of subjectivity that affect the source duration estimates. In cases when the source locations of two earthquakes are almost identical and when they are recorded by the same stations, one would expect that the slope of these regression models would have been very close if objective methods are used.

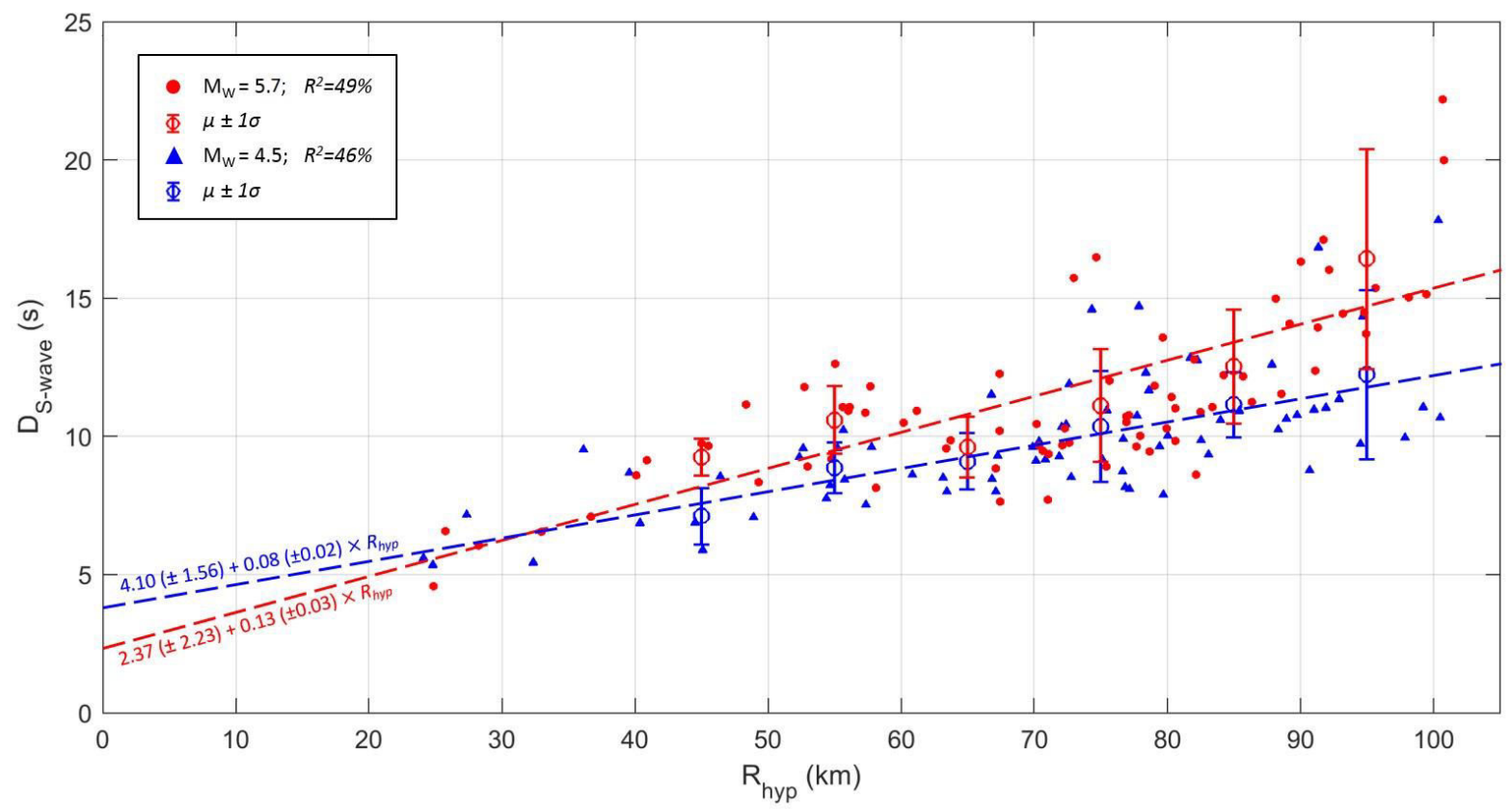

Fig. 4 Duration of hand-picked S-wave windows versus hypocentral distance; bars represent the error range as $\pm 1 \sigma$, while the empty circles are the mean values, $\mu$; dashed lines are first-degree polynomial fittings for each magnitude separately.

The path component of S-wave durations is modelled linearly as $0.1 \times \mathrm{R}_{\text {hyp }}$ for California, in seconds (Kishida et al 2016). The empirical factor of 0.1 in this expression matches well with the path components of our models, which are $0.08( \pm 0.02)$ and $0.13( \pm 0.03)$. In Kishida et al. (2016), source durations for events with magnitudes of $M_{W} \leq 4.5$ that occurred in Greece is roughly between 8-10 seconds - which is much higher than our findings. In the same study, a 10 -second source duration is suggested for events with $M_{W} \leq 4.5$. 


\subsection{Significant duration}

Significant duration is defined as the time interval across which a certain amount of energy is dissipated. Arias (1970) used the integral of the square of the ground acceleration to represent energy, which is commonly known as Arias Intensity $\left(\mathrm{I}_{\mathrm{A}}\right)$,

$$
I_{A}=\frac{\pi}{2 g} \int_{0}^{T} a^{2}(t) d t
$$

where $\mathrm{g}$ is the gravitational acceleration, $\mathrm{T}$ is total duration of strong ground motion and $\mathrm{a}(\mathrm{t})$ represents acceleration time history, and. Velocity time histories can also be used to define energy as the integral velocity, introduced by Sarma (1970).

We considered the two widely used measures of significant duration. These two measures are expressed as the time interval needed to accumulate $5-75 \%$ and $5-95 \%$ of $\mathrm{I}_{\mathrm{A}}$. They will be denoted as $\mathrm{SD}_{5-75}$ and $\mathrm{SD}_{5-95}$ hereafter. We present significant durations for three components, plotted against hypocentral distance. The linearity of these distributions and fitted first-degree polynomial lines are checked as well. The R-squared values of the distributions of horizontal components are relatively lower than that of the vertical component. Therefore, the \pm 95 confidence intervals of the fitted first-degree polynomials are higher in horizontal components than in the vertical component (Table 4). In this regard, the highest R-squared values with tightest confidence intervals are of $\mathrm{SD}_{5-75}$ of the vertical component, showing the best compatibility with linear regression. The resulting source durations are $2.90 \pm 1.85 \mathrm{~s}$ and $2.74 \pm 2.08 \mathrm{~s}$ for $\mathrm{M}_{\mathrm{w}} 4.5$ and for $\mathrm{M}_{\mathrm{w}} 5.7$ events, respectively. These values are in good agreement with the observed source durations for S-waves. Moreover, the path components of the same regressions are $0.13 \pm 0.03$ and $0.12 \pm 0.03$. This term is 0.1 for events with M3.1-6.7 in Southern California (Raoof et al. 1999) and 0.07 and 0.15 in Kempton and Stewart (2006) for $\mathrm{SD}_{5-75 \%}$ and $\mathrm{SD}_{5-95 \%}$, respectively. All these values are very similar with our estimations. However, the same term is 0.05 for moderate magnitude earthquakes in eastern North America (Atkinson 1993). From visual check of individual time series and from duration distributions against hypocentral distance, we infer that the $\mathrm{SD}_{5-75}$ appears to be a favourable representation of the strong shaking window for these earthquakes (Fig. 5, Fig. 6). 

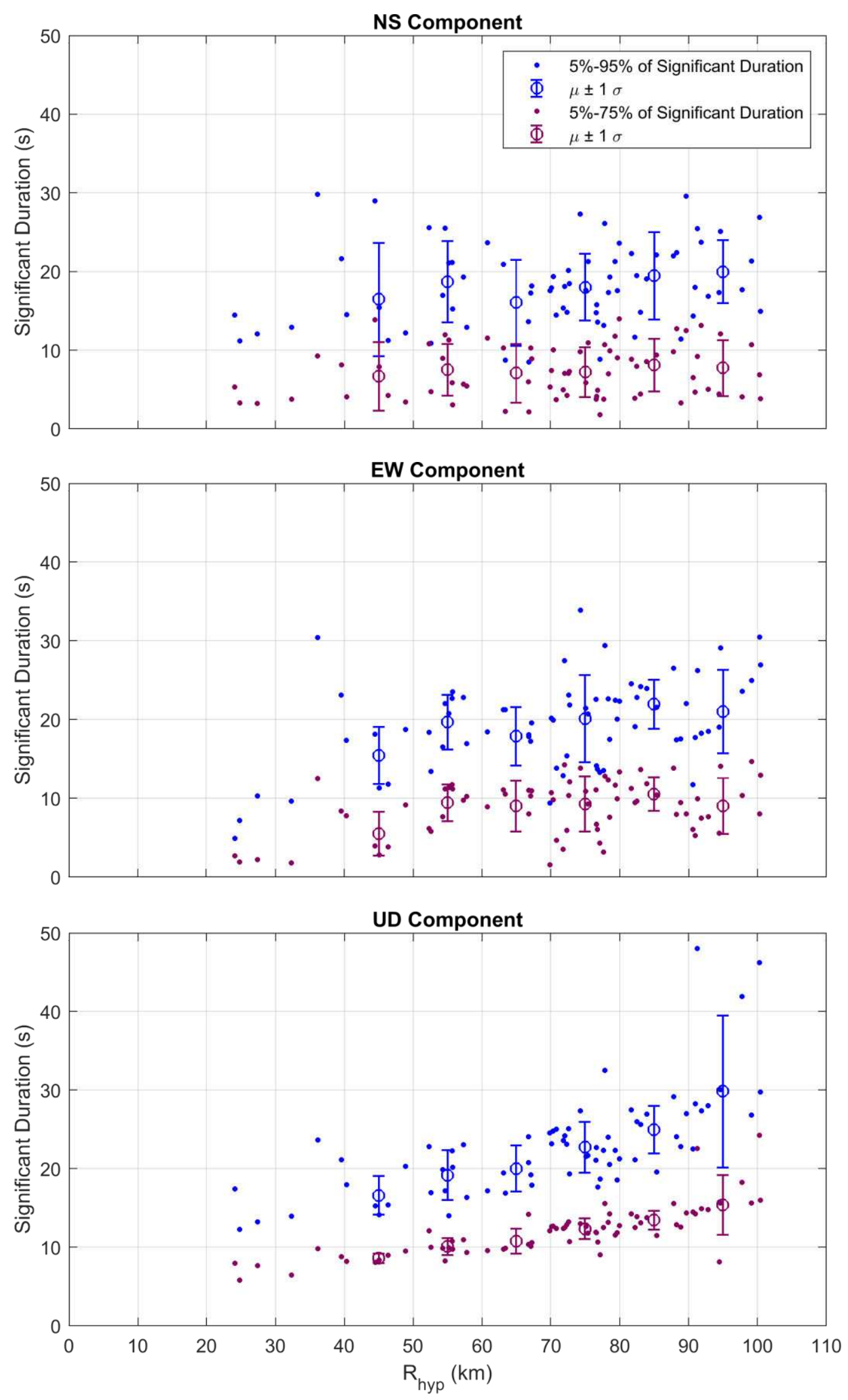

Fig. 5 Significant durations of the $\mathrm{M}_{\mathrm{W}} 4.5$ event. The blue and purple data points show the durations needed to accumulate $5 \%-75 \%$ and $5 \%-95 \%$ of the energy, respectively; whereas, the error bars represent $\mu \pm 1 \sigma$. 

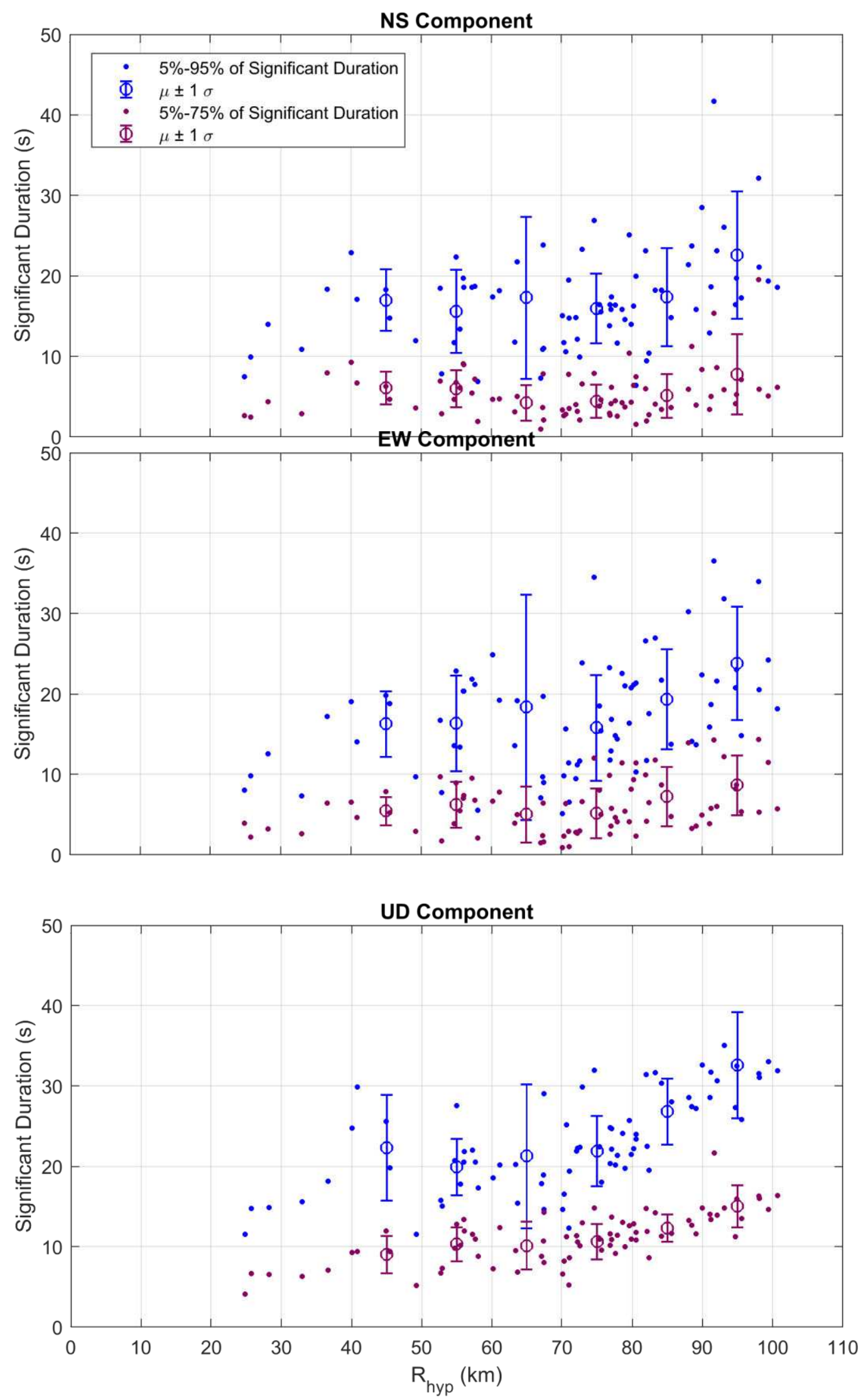

Fig. 6 Significant durations of the $\mathrm{M}_{\mathrm{w}} 5.7$ event. The blue and purple data points show the durations needed to accumulate 5\%-75\% and 5\%-95\% of the energy, respectively; whereas, the error bars represent $\mu \pm 1 \sigma$. 
Table $4 \mathrm{R}^{2}$ estimations of the data distribution in Figure 5 and Figure 6 and fittings in the form of $a+b \times R_{\text {hyp }}$ for $\mathrm{M}_{\mathrm{w}} 4.5$ and $\mathrm{M}_{\mathrm{w}} 5.7$ events.

\begin{tabular}{|c|c|c|c|c|c|c|c|}
\hline & & \multicolumn{3}{|c|}{ Significant Duration (5\%-75\%) } & \multicolumn{3}{|c|}{ Significant Duration (5\%-95\%) } \\
\hline & & $R^{2}(\%)$ & $a$ & $b$ & $R^{2}(\%)$ & $a$ & $b$ \\
\hline \multirow{3}{*}{$M_{W} 4.5$} & $N S$ & 25 & $5.24 \pm 2.98$ & $0.03 \pm 0.04$ & 42 & $14.26 \pm 4.69$ & $0.06 \pm 0.06$ \\
\hline & $E W$ & 16 & $3.60 \pm 2.92$ & $0.07 \pm 0.04$ & 20 & $10.06 \pm 4.68$ & $0.14 \pm 0.06$ \\
\hline & $U D$ & 60 & $2.90 \pm 1.85$ & $0.13 \pm 0.03$ & 41 & $7.00 \pm 4.60$ & $0.22 \pm 0.06$ \\
\hline \multirow{3}{*}{$M_{w} 5.7$} & $N S$ & 35 & $3.11 \pm 2.75$ & $0.03 \pm 0.04$ & 13 & $8.52 \pm 5.23$ & $0.12 \pm 0.07$ \\
\hline & $E W$ & 11 & $1.77 \pm 2.94$ & $0.06 \pm 0.04$ & 16 & $6.58 \pm 5.86$ & $0.15 \pm 0.08$ \\
\hline & $U D$ & 48 & $2.74 \pm 2.08$ & $0.12 \pm 0.03$ & 40 & $6.99 \pm 4.85$ & $0.23 \pm 0.07$ \\
\hline
\end{tabular}

\section{Engineering Parameters}

Peak ground motion parameters and spectral quantities have been calculated for each horizontal component of acceleration traces. Station specific $\mathrm{V}_{\mathrm{s}, 30}$ values have been inferred from Istanbul Metropolitan Municipality's $\mathrm{V}_{\mathrm{s}, 30}$ maps for Istanbul IMM (2007 \& 2009). The $\mathrm{V}_{\mathrm{s}, 30}$ values of eight stations, the locations of which are not covered by these maps, have been obtained from the QTM (Quaternary, Tertiary, Mesozoic) map of Turkey by General Directorate Mineral Research and Exploration (MTA 2004).

Figure $7 \mathrm{a} \& \mathrm{~b}$ feature the spatial distributions of stations considering the geometric means of peak ground accelerations (PGAs) for both events. The figure explicitly unveils the decrease in PGAs at the further epicentral distances while the stations at the immediate north coast of Marmara Sea, which are the closest mainland to the epicentres, present relatively larger PGAs. It is striking that there exists no PGA greater than $4 \mathrm{~cm} / \mathrm{s}^{2}$ beyond $60 \mathrm{~km}$ of epicentral distance for $\mathrm{M}_{\mathrm{W}} 4.5$ event and similarly, only $4 \%$ of the stations (stations of FBZMD\&3411 at slightly further than $60 \mathrm{~km}$ of epicentral distance) exhibit PGAs greater than $30 \mathrm{~cm} / \mathrm{s}^{2}$ for $\mathrm{M}_{\mathrm{W}} 5.7$ event.

Distribution of the geometric mean of PGAs and peak ground velocities (PGVs) is also illustrated in Figure 8 and Figure 9 to evaluate the variation of these parameters with respect to epicentral distance and average shear wave velocities of stations for the upper $30 \mathrm{~m}$ depth $\left(\mathrm{V}_{\mathrm{s}, 30}\right)$.

Initial evaluation shows that soft soils and proximity to the epicentre increase the PGAs and PGVs compared with the further distance and stiffer soil records. However, a detailed examination unveils some exceptions which will be detailed in what follows. 


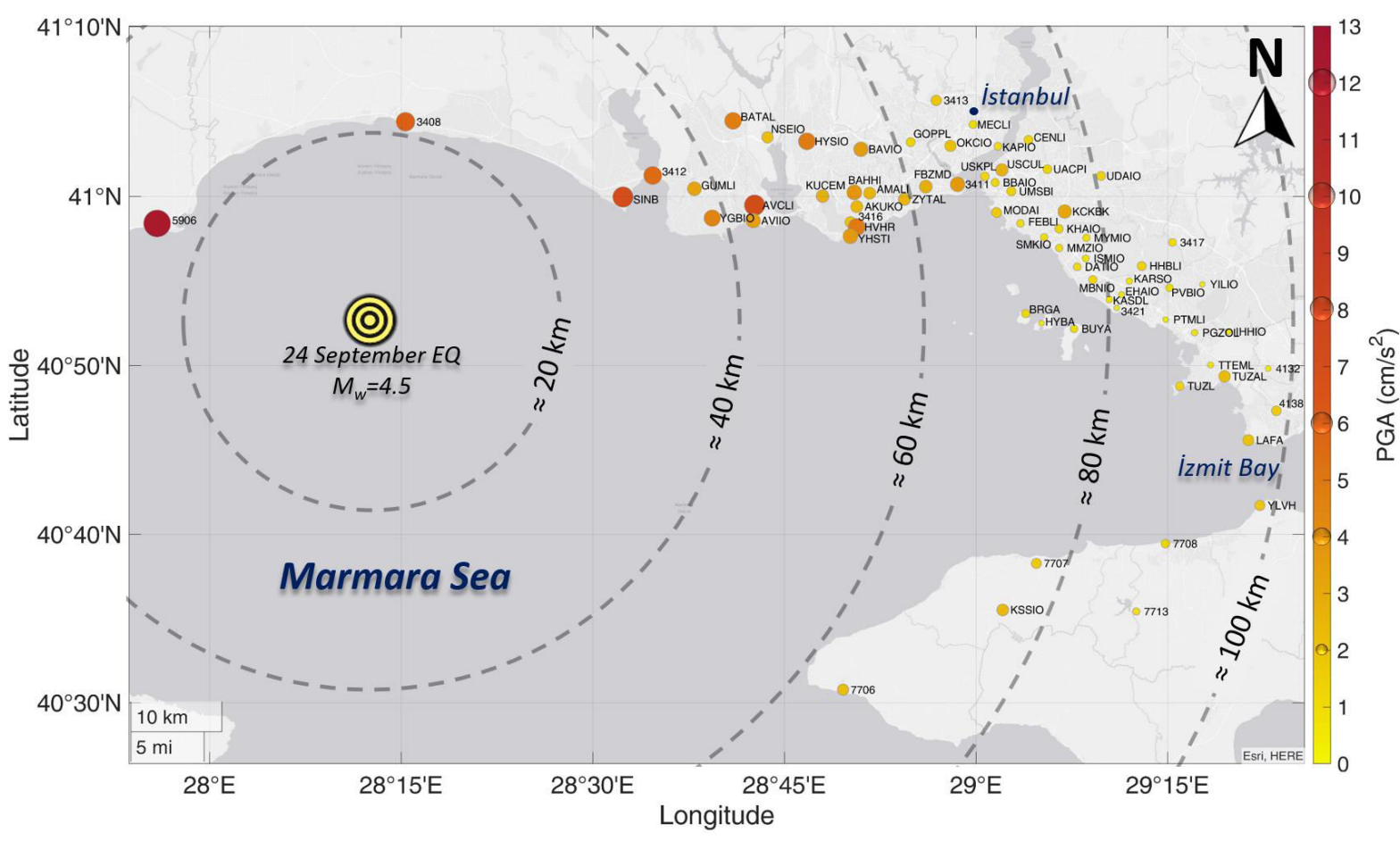

(a)

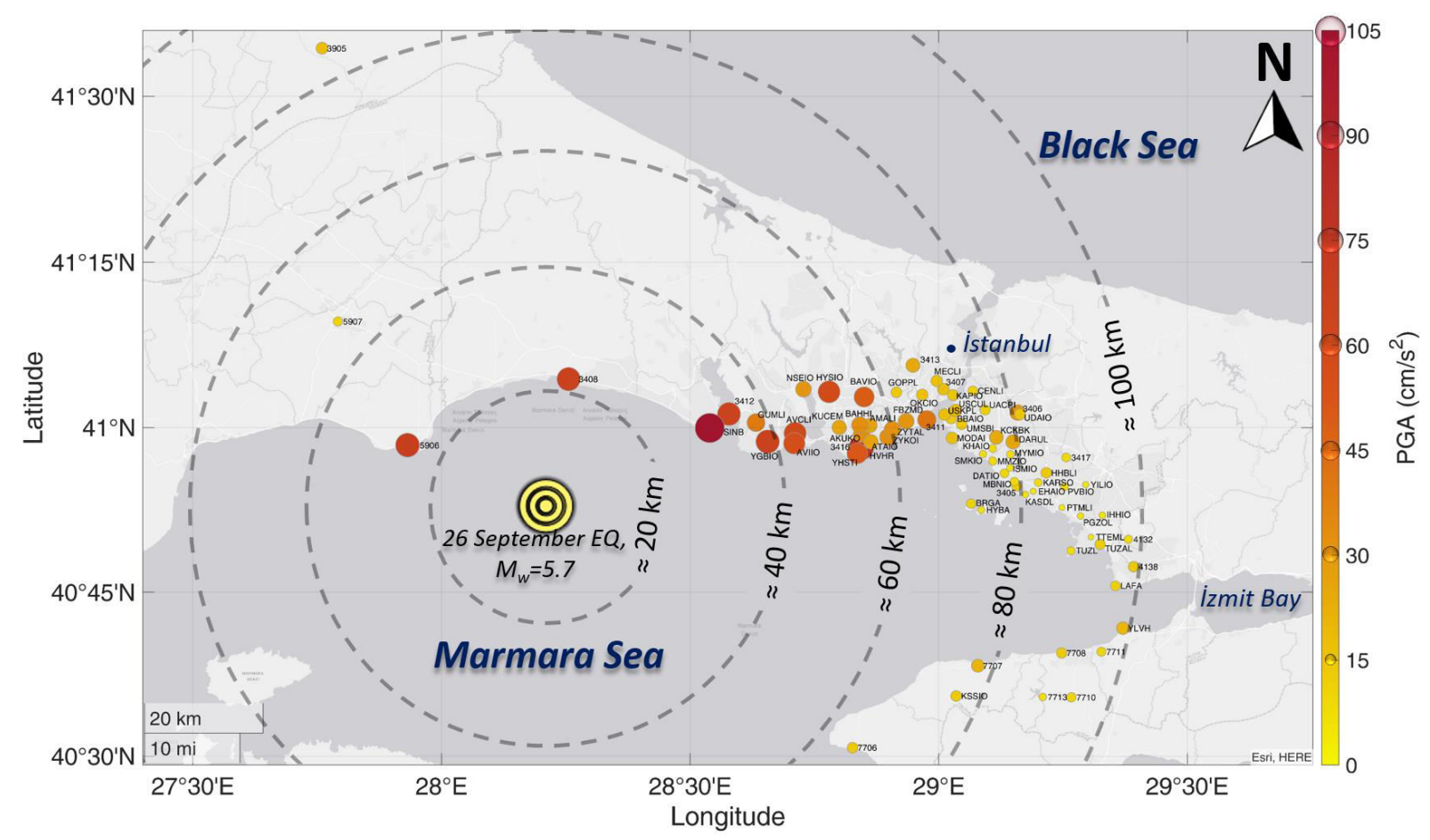

(b)

Fig. 7 Spatial distribution of PGAs for (a) $M_{w} 4.5$ event, (b) $M_{w} 5.7$ event (PGAs are calculated as the geometric mean of two horizontal components; dashed circles designate the epicentral distances). 
For $M_{W} 4.5$ earthquake, one of the closest stations of AFAD, 5906, deployed on relatively soft soil conditions provides the largest PGA value as about $13 \mathrm{~cm} / \mathrm{s}^{2}$. At a similar distance, another AFAD station (3408), the closest one to the epicentre, gives a lower value than 5906. This may be associated with relatively stiffer soil conditions of station 3408 compared to station 5906 . However, component-based peak values reveal that the PGA of the EW component of the closest station is identical to that of station 5906 while its NS component exhibits remarkably lower PGA than station 5906 (Fig. 8a). Another striking point is that the EW components at stations having epicentral distances less than $50 \mathrm{~km}$ are larger than their NS counterparts except for the AVCLI station. Moreover, PGV of the EW component of station 3408 is slightly greater than that of 5906, while the difference between the PGVs of NS components is significant (Fig. 8b).It should also be noted that the stations associated with higher PGA and PGV values, are at locations very close to the northern coast of the Marmara Sea. Another feature that comes forward from Figure 8a and Figure 8b is the seeming existence of two zones that are marked with strikingly different average PGA and PGV levels separated at about $60 \mathrm{~km}$. We will elaborate more on this in the next section.

Similar to PGAs and PGVs, spectral accelerations (SAs) reach their maxima in EW components (Fig. 8a). For closer stations with $\mathrm{V}_{\mathrm{s}, 30}$ values lower than $250 \mathrm{~m} / \mathrm{s}$ (3412 \& 5906), elastic acceleration response spectra show a bump at periods near $0.1 \mathrm{~s}$. However, the response spectra of recordings from the other three stations (3408, AVCLI, SINB; $V_{s, 30}>250 \mathrm{~m} / \mathrm{s}$ ) with largest PGAs and PGVs give maximum accelerations at the period of around $0.2 \mathrm{~s}$.

From the PGA distribution of the $\mathrm{M}_{\mathrm{W}} 5.7$ event, it is seen that recordings from four stations (5906, 3408, SINB, HVHR) generate relatively high PGAs (Fig. 9a). SINB of IERREWS, the third closest station to the epicentre $\left(\mathrm{R}_{\text {epi }} \approx 31 \mathrm{~km}\right)$ registers the largest PGA as $145.8 \mathrm{~cm} / \mathrm{s}^{2}$ in the EW component. Although 5906 is the second closest station and located on a site with the lowest $\mathrm{V}_{\mathrm{s}, 30}$ value $\left(\mathrm{V}_{\mathrm{s}, 30} \approx 225 \mathrm{~m} / \mathrm{s}\right)$ among the closest stations, the PGA of its EW component is lower than that of SINB, which possesses a slightly larger $\mathrm{V}_{\mathrm{s}, 30}$ and is at a similar epicentral distance. However, their NS component-PGAs are about identical. The PGV distribution is shown in Figure $9 \mathrm{~b}$ and includes interesting features worth discussing. The largest PGV is registered in the EW component of station SINB similar to its PGA; however, the maximum of geometric mean PGV is associated with station HVHR deployed at an intermediate epicentral distance $\left(\mathrm{R}_{\mathrm{epi}} \approx 54 \mathrm{~km}\right)$. As a general observation the largest PGVs are recorded at stations at epicentral distances less than $60 \mathrm{~km}$ and that have $\mathrm{V}_{\mathrm{s}, 30}$ values less than $350 \mathrm{~m} / \mathrm{s}$. The two zones separated at about $60 \mathrm{~km}$ epicentral distance and characterized by two distinctly different average PGA and PGV levels realized for the case of the $M_{w} 4.5$ event, exists for this larger event as well. As mentioned earlier they will be discussed further with the help of GMPEs. 


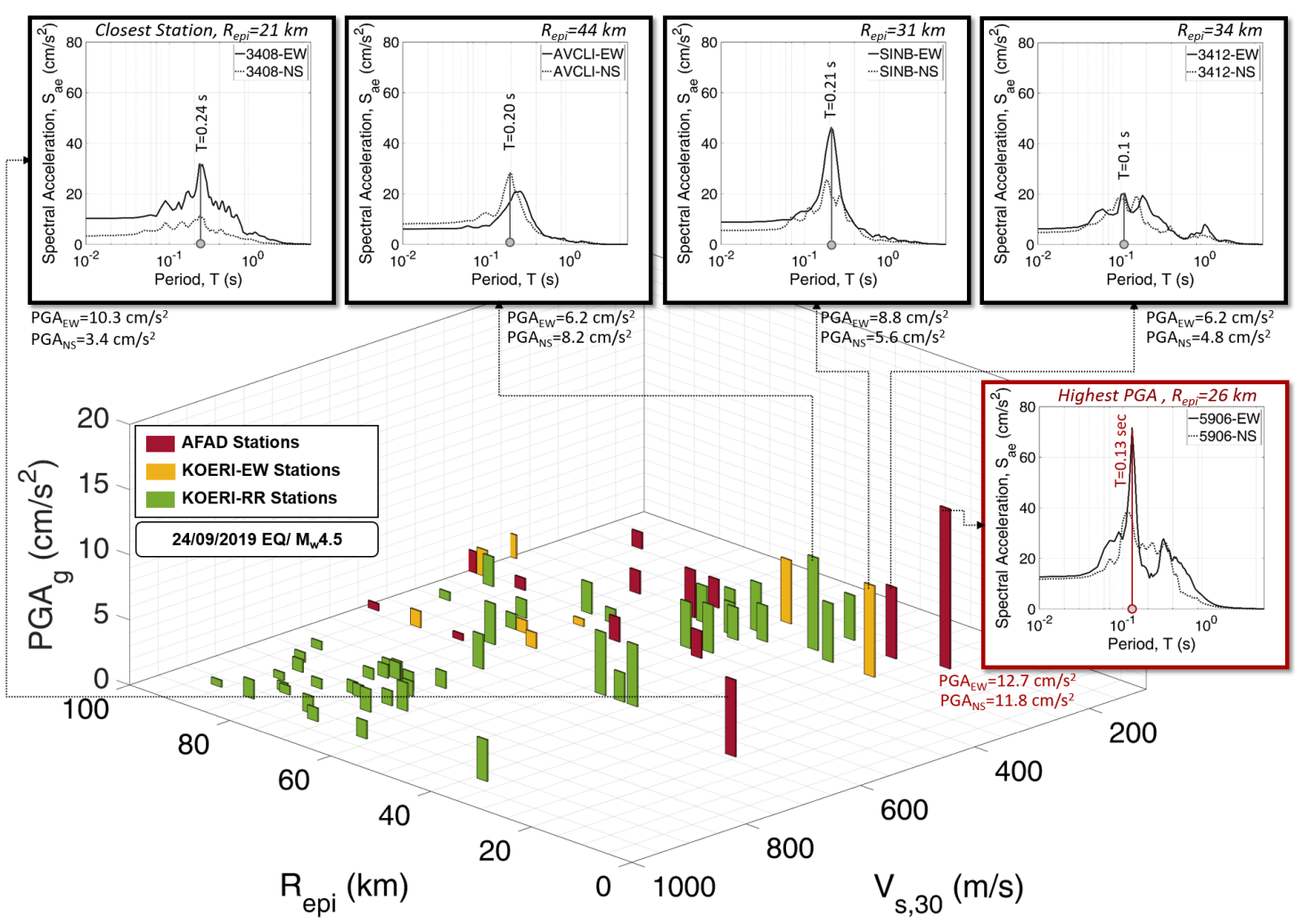

(a)

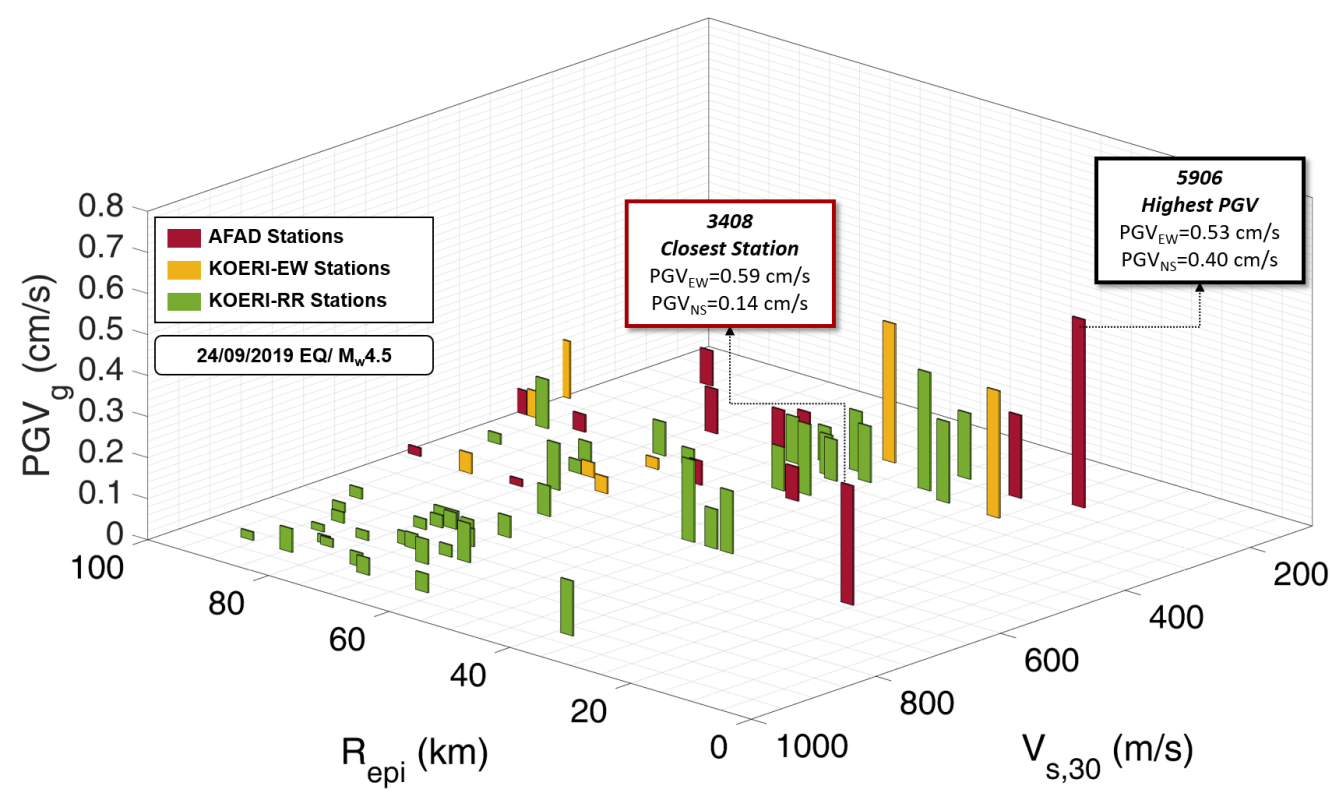

(b)

Fig. 8 Variation of PGAs and elastic response spectra of single degree of freedom systems (SDOF) for selected records (a) and variation of PGVs (b) as a function of epicentral distance and $V_{s, 30}$ for the $\mathrm{M}_{\mathrm{W}} 4.5$ earthquake. 


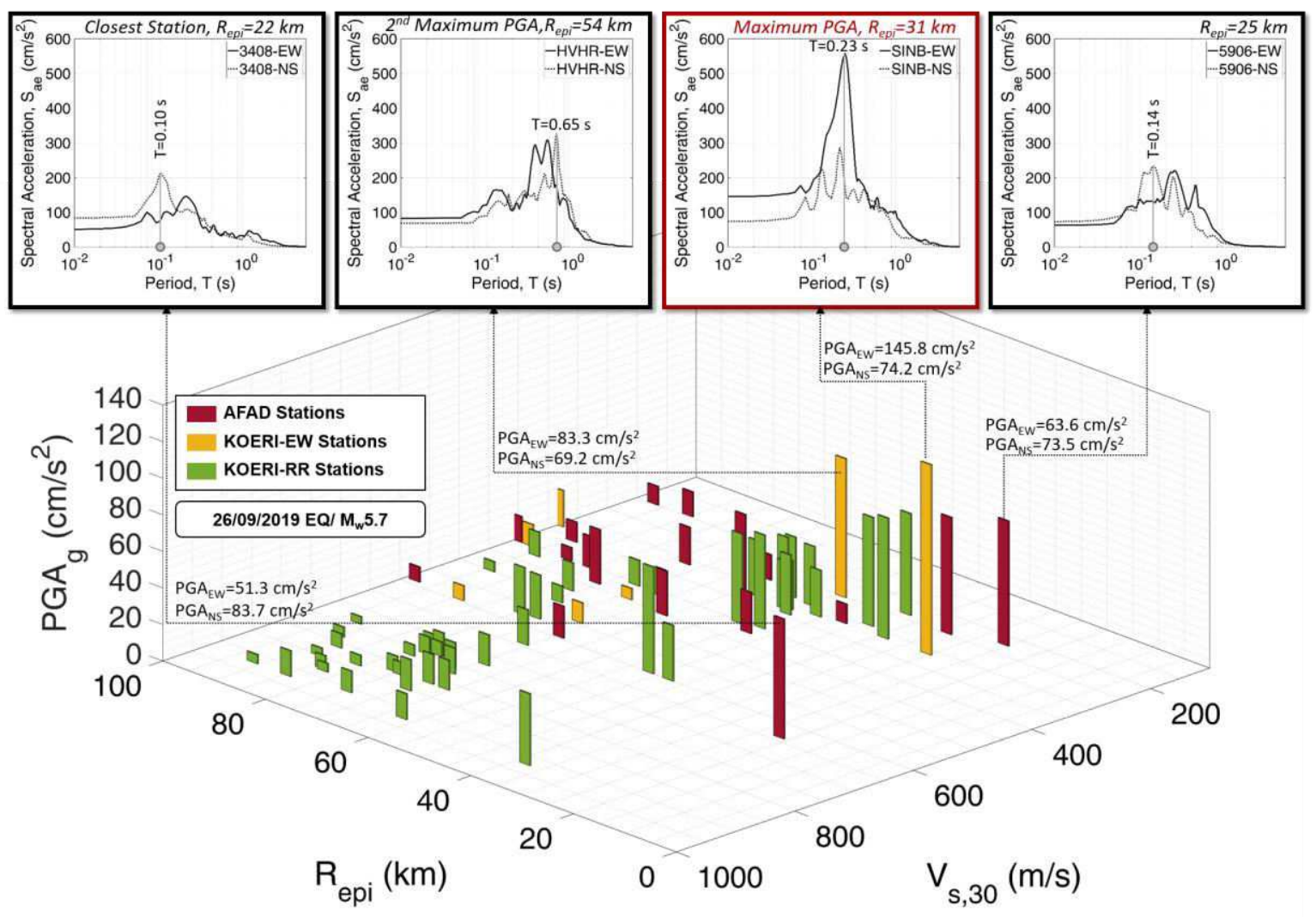

(a)

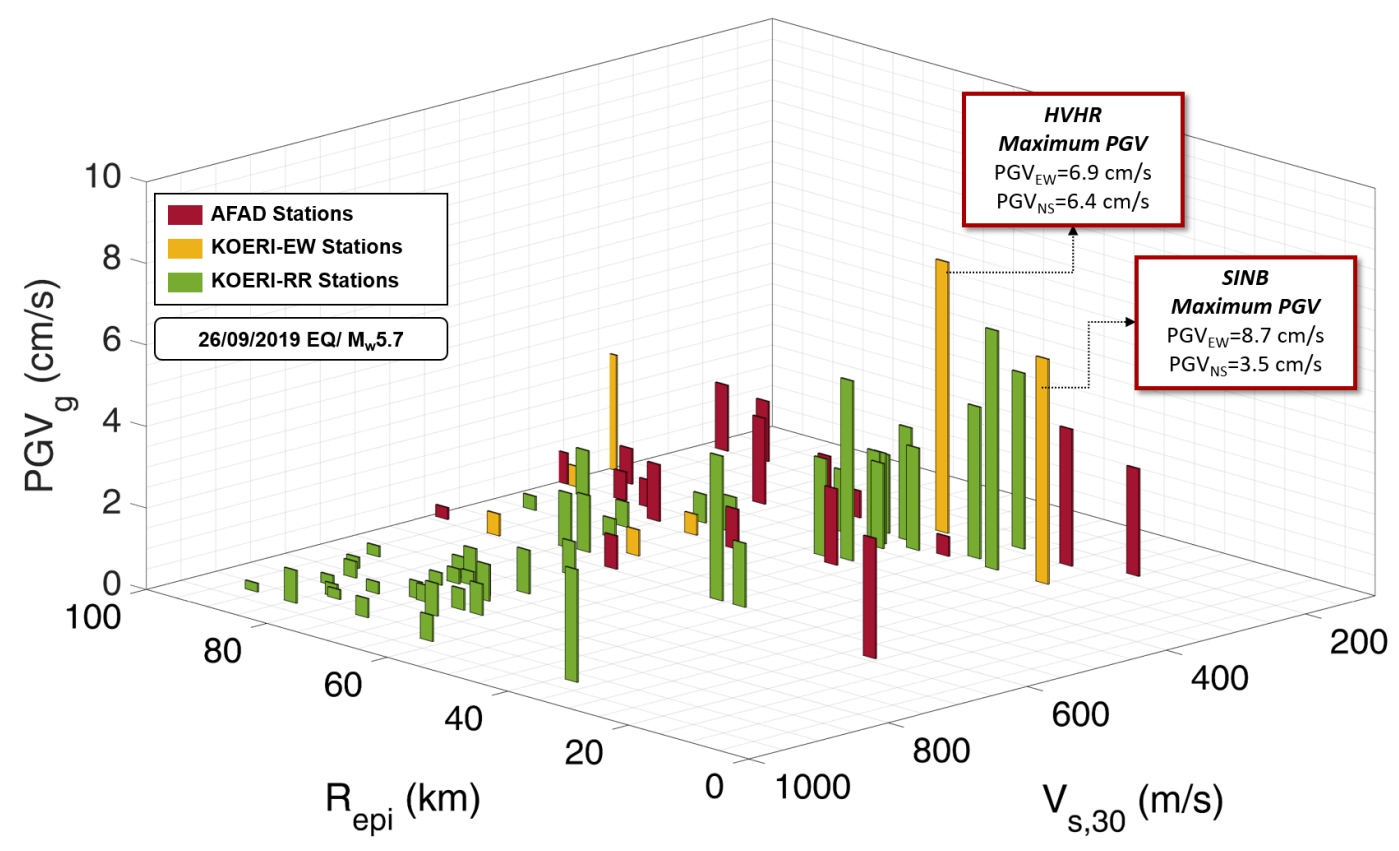

(b)

Fig. 9 Variation of PGAs and elastic response spectra of single degree of freedom systems (SDOF) for selected records (a) and variation of PGVs (b) as a function of epicentral distance and $\mathrm{V}_{\mathrm{s}, 30}$ for the $\mathrm{M}_{\mathrm{w}} 5.7$ earthquake. 
For the $\mathrm{M}_{\mathrm{w}}$ 5.7 earthquake, response spectral amplitudes follow the trend observed for the PGAs (Fig. 9a). The EW component of station SINB generates a very high salient peak SA $(\approx 558$ $\left.\mathrm{cm} / \mathrm{s}^{2}\right)$ at $0.23 \mathrm{~s}$. However, its NS component produces compatible SAs with other three stations (3408, HVHR \& 5906). NS components of the closest stations, 3408 and 5906, also have high SAs at the periods around $0.1 \mathrm{~s}$. The EW components of these stations have SA peaks around 0.2 and 0.25 seconds, respectively. It is worth noting that stations $3408\left(\mathrm{~V}_{\mathrm{s}, 30} \approx 639 \mathrm{~m} / \mathrm{s}\right)$ and 5906 $\left(\mathrm{V}_{\mathrm{s}, 30} \approx 225 \mathrm{~m} / \mathrm{s}\right)$ produce similar levels of SAs at similar frequencies although they have different soil conditions. Furthermore, while the EW component of HVHR station experiences two high SA peaks between $0.3-0.6$ s periods, the maximum SA $\left(\approx 300 \mathrm{~cm} / \mathrm{s}^{2}\right)$ arises in NS component around $0.65 \mathrm{~s}$, which corresponds to relatively longer periods.

Discussions above motivate the comparison of recorded ground motion peaks with established GMPEs, which is the subject of the next section.

\section{Comparison with GMPEs}

\subsection{Selected Ground Motion Prediction Equations}

PGAs, PGVs and SAs are compared with three commonly used GMPEs in the region to understand the attenuation characteristics of observed data as a function of epicentral distance. Selected equations are as in the following: Boore et al. 2014 (BSSA14), Akkar et al. 2014 (ASB14) and Kale et al. 2015 (KAAH15). Information on the input parameters of these expressions and the values that we used as well as our assumptions in employing them are given below.

- Moment magnitude ( $M_{W}$ ): Moment magnitudes are taken as 4.5 and 5.7 for $24^{\text {th }}$ September and $26^{\text {th }}$ September earthquakes respectively, as given by KOERI.

- Distance (R): BSSA14 and KAAH15 adopt Joyner-Boore distance $\left(\mathrm{R}_{\mathrm{JB}}\right)$, while ASB14 uses $\mathrm{R}_{\text {epi. }}$. For the $\mathrm{M}_{W} 4.5$ event, due to lack of a fault plane solution, we have assumed that $\mathrm{R}_{J B}$ equals to epicentral distance $\left(R_{e p i}\right)$. As for the $M_{w} 5.7$ event, Karabulut et al. (2021) suggested an elliptic finite-fault model, whose rupture zone has a length of $5 \mathrm{~km}$ on the east and $3 \mathrm{~km}$ on west of the epicentre. There is about $8 \%$ and $3 \%$ decrement in distance when $R_{J B}$ with respect to its surface projection is considered instead of $R_{e p i}$ for stations 3408 (closest) and YLVH (farthest) respectively. This is a difference which will have a relatively insignificant effect on our general evaluations. Therefore, we have preferred to use $R_{\text {epi }}$ for the $M_{w} 5.7$ event as well. Eventually $R_{\text {epi }}$ has been the distance definition that we adopted for the three GMPEs .

- Fault type (SoF): Style of faulting is accepted as strike-slip for both $\mathrm{M}_{\mathrm{w}} 4.5$ and $\mathrm{M}_{\mathrm{w}} 5.7$ events based on Karabulut et al. (2021). 
- Average shear wave velocity for the upper $30 \mathrm{~m}$ depth $\left(V_{s, 30}\right)$ : For the data set, mean $V_{s, 30}$ have been computed as $600 \mathrm{~m} / \mathrm{s}$ and GMPEs have been estimated using this value. According to NEHRP site classification, this value corresponds to "Soil Class C: very dense soil and soft rock', whose $\mathrm{V}_{\mathrm{s}, 30}$ values are between $360-760 \mathrm{~m} / \mathrm{s}$.

- Region: BSSA14 and KAAH15 offer regional options. Parameter values corresponding to Turkey have been utilized in the generation of GMPE curves. ASB14 does not specify any option for any region. However, since ASB14 were derived from strong ground motion records obtained in the Mediterranean region and the Middle East, they could directly be used without any regional modification.

\subsection{Variation of Peak Ground Motion Parameters}

Median level PGAs and PGVs estimated by the three previously mentioned GMPEs, as well as corresponding bounds for standard deviations $(\sigma)$ (median $\pm \sigma$ \& median $\pm 2 \sigma$ lines) are shown in Figure 10. There are no records at distances less than $10 \mathrm{~km}$. Therefore, the considered distance range in Figure 10. is $10-100 \mathrm{~km}$. The recorded PGAs and PGVs plotted correspond to the geometric mean of two horizontal components (East-West and North-South).

When PGAs are compared with the estimations of BSSA14 for both earthquakes, observed values up to about $60 \mathrm{~km}$ mainly remain within the median $\pm \sigma$ interval. However, with the increase in epicentral distance, observed PGAs start to decay faster than BSSA14. While a few observed PGAs approach to the median-2 $\sigma$ line (2.3 ${ }^{\text {rd }}$ percentile) for the smaller event, for the larger event, there is an observed PGA cluster below $-2 \sigma$ line after about $70 \mathrm{~km}$. For $\mathrm{M}_{\mathrm{w}} 4.5$ earthquake, ASB14 and KAAH15 appear to have a better agreement with observed PGAs varying between $16^{\text {th }}$ and $84^{\text {th }}$ percentile (median $\pm \sigma$ ) prediction lines with a few exceptions. PGAs of $\mathrm{M}_{\mathrm{W}} 5.7$ event seem to be underestimated by ASB14 and KAAH15 up to about $70 \mathrm{~km}$ of distance, beyond which they begin to approach the median lines and at further distances, they arrive at $16^{\text {th }}$ percentile line. To sum up, for both earthquakes, faster attenuation is unveiled in the observed PGAs especially above the distances around 60 - $70 \mathrm{~km}$ compared with GMPE predictions.

The PGVs of both events are more dispersed than the PGAs. For $\mathrm{M}_{\mathrm{W}} 4.5$ earthquake, observed PGVs are within the median $\pm \sigma$ band of three selected GMPEs up to epicentral distances around $60-70 \mathrm{~km}$. Beyond this distance, PGVs display a sharp reduction down to the median-2 $\sigma$ line. The dispersion of PGVs is larger in the case of the $\mathrm{M}_{\mathrm{W}} 5.7$ event. Similar to the observations we made about the PGAs and the PGVs of the $\mathrm{M}_{\mathrm{W}} 4.5$, two distance ranges are easily identified, in which the PGV attenuation has different trends. They seem to separate at about $50 \mathrm{~km}$. At distances smaller than approximately $50 \mathrm{~km}$, the PGVs follow the trend set by the GMPEs, although the majority of them are above the median. After $50 \mathrm{~km}$, they start to attenuate faster than the GMPE estimates. , on a general path that quickly approaches the median- $2 \sigma$ line. 

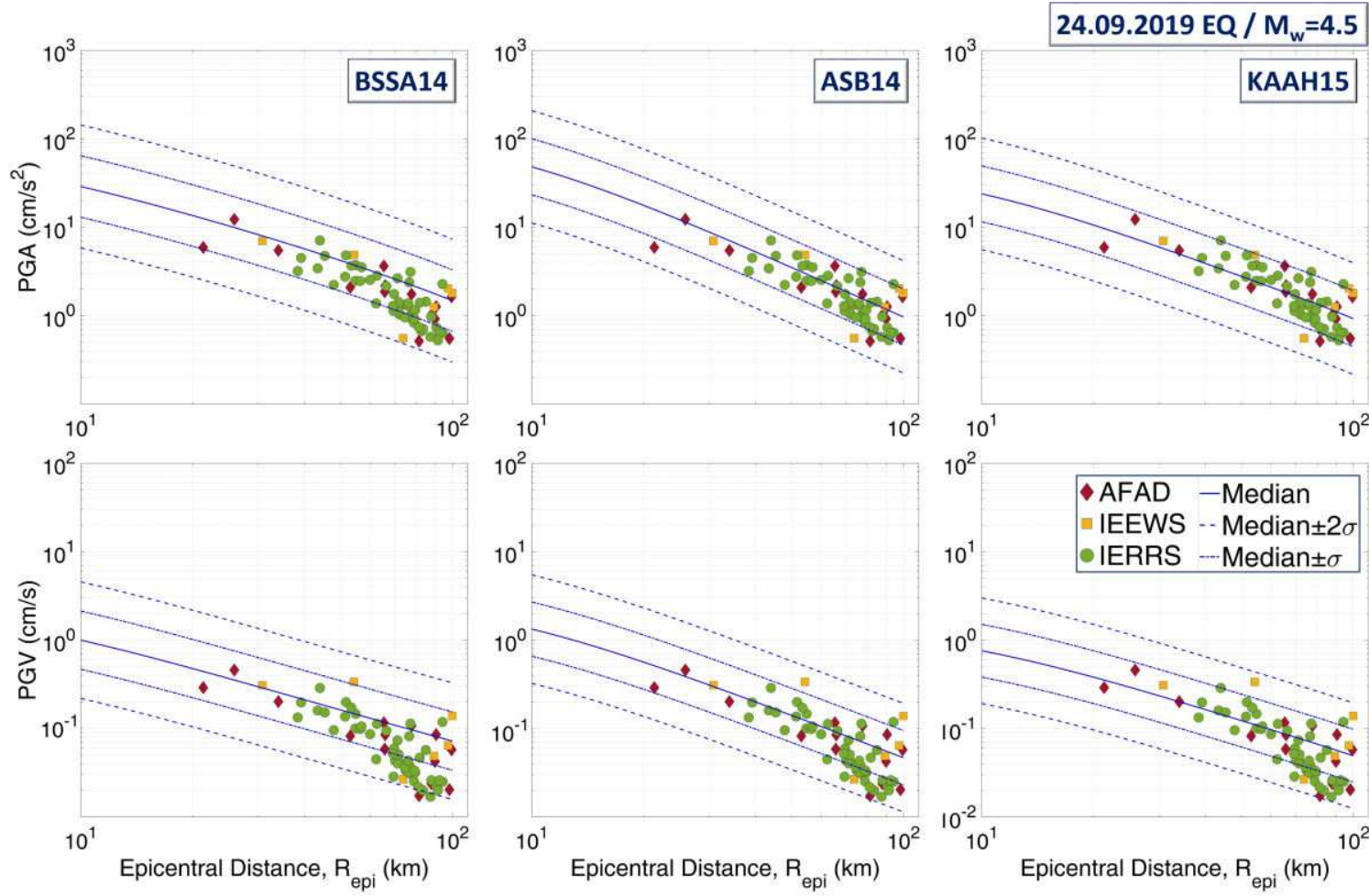

(a)
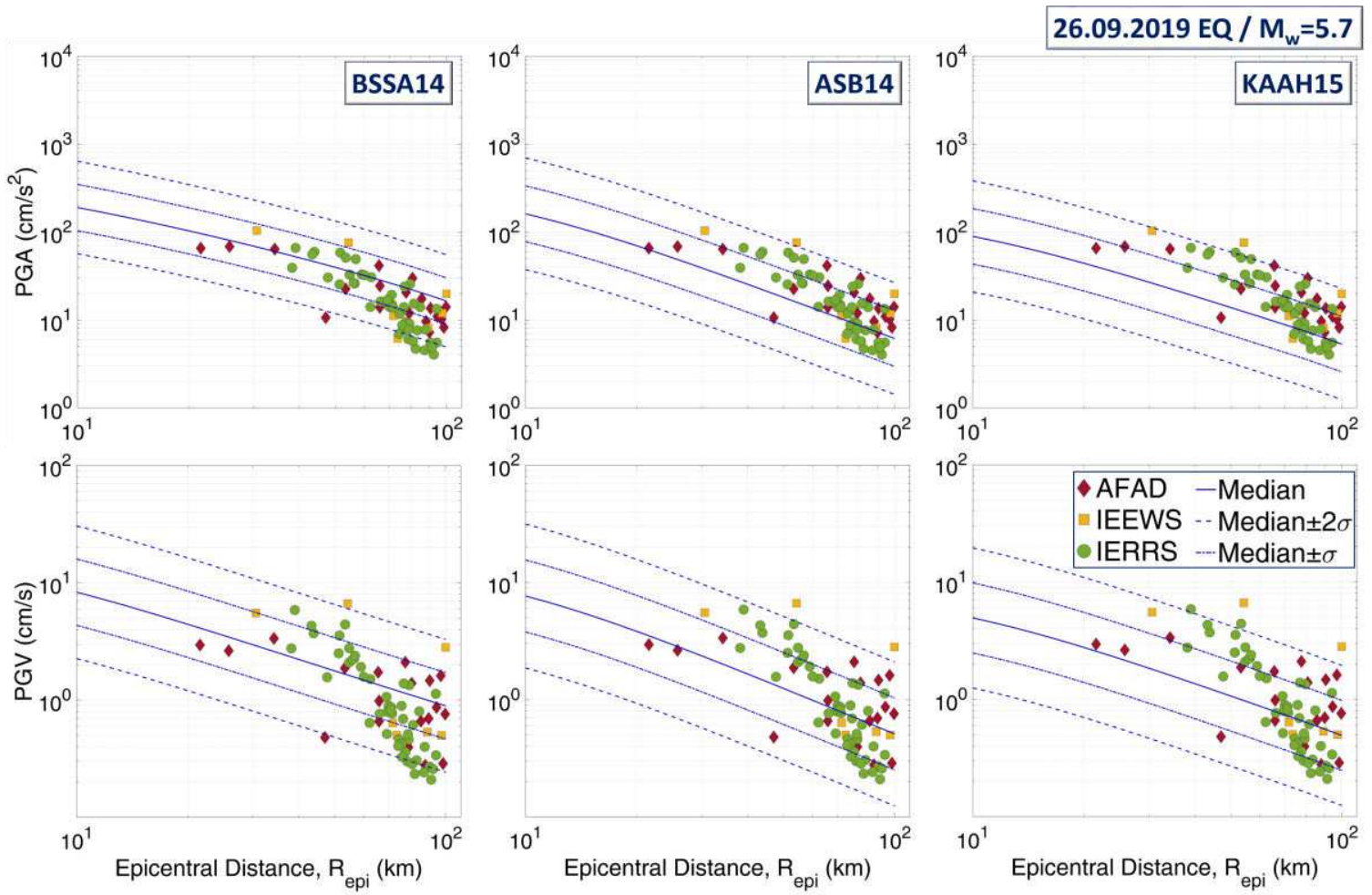

(b)

Fig. 10 Variation of PGAs and PGVs with epicentral distance for (a) $M_{W} 4.5$ earthquake (b) $M_{W} 5.7$ earthquake and comparison with GMPEs, BSSA14, ASB14 and KAAH15. 


\subsection{Variation of Spectral Accelerations}

SAs have been examined for four different periods (T), namely, $\mathrm{T}=0.4 ; 1.0 ; 2.0$ and $4.0 \mathrm{~s}$. In order to pinpoint explicitly the extent to which observed spectral amplitudes in different periods conform with GMPEs, the observed and estimated SAs are depicted in Figure 11 and Figure 12 for $\mathrm{M}_{\mathrm{W}} 4.5$ and $\mathrm{M}_{\mathrm{W}} 5.7$ events respectively.

At first glance, the notable feature that can be detected in Figure 11 is the over-prediction of SAs by three selected GMPEs after about $60 \mathrm{~km}$ of distance for the $\mathrm{M}_{\mathrm{W}} 4.5$ earthquake. On the other hand, for short periods, i.e. $\mathrm{T}=0.4 \mathrm{~s} \& 1.0 \mathrm{~s}$, the observed SAs are within the range of $2.3^{\mathrm{rd}}$ and $98^{\text {th }}$ percentiles but the majority of the data are very close to the latter. With the increase in the period, the overestimations become clearer and observed values are descended below the $98^{\text {th }}$ percentiles. Before $60 \mathrm{~km}$, SAs are generally within one standard deviation range of three selected GMPEs for all periods.

Beneath $60 \mathrm{~km}$, the majority of SAs of the $\mathrm{M}_{\mathrm{W}} 5.7$ event take larger values than GMPEs' estimations except for SAs at $\mathrm{T}=4.0 \mathrm{~s}$, where a relatively better agreement with median lines is evident. Beyond this distance threshold, SAs start to attenuate faster. While this is more explicit in SAs with $\mathrm{T}=0.4 \mathrm{~s}$, SAs at greater periods are assembled around the $16^{\text {th }}$ percentile line for $\mathrm{T}=1.0 \& 2.0 \mathrm{~s}$ and the $2.3^{\text {rd }}$ percentile for $\mathrm{T}=4.0 \mathrm{~s}$. At the furthest distances, wide dispersion of observed SAs which extend beyond the $2.3^{\text {rd }}$ and $98^{\text {th }}$ percentile predictions is evident. 

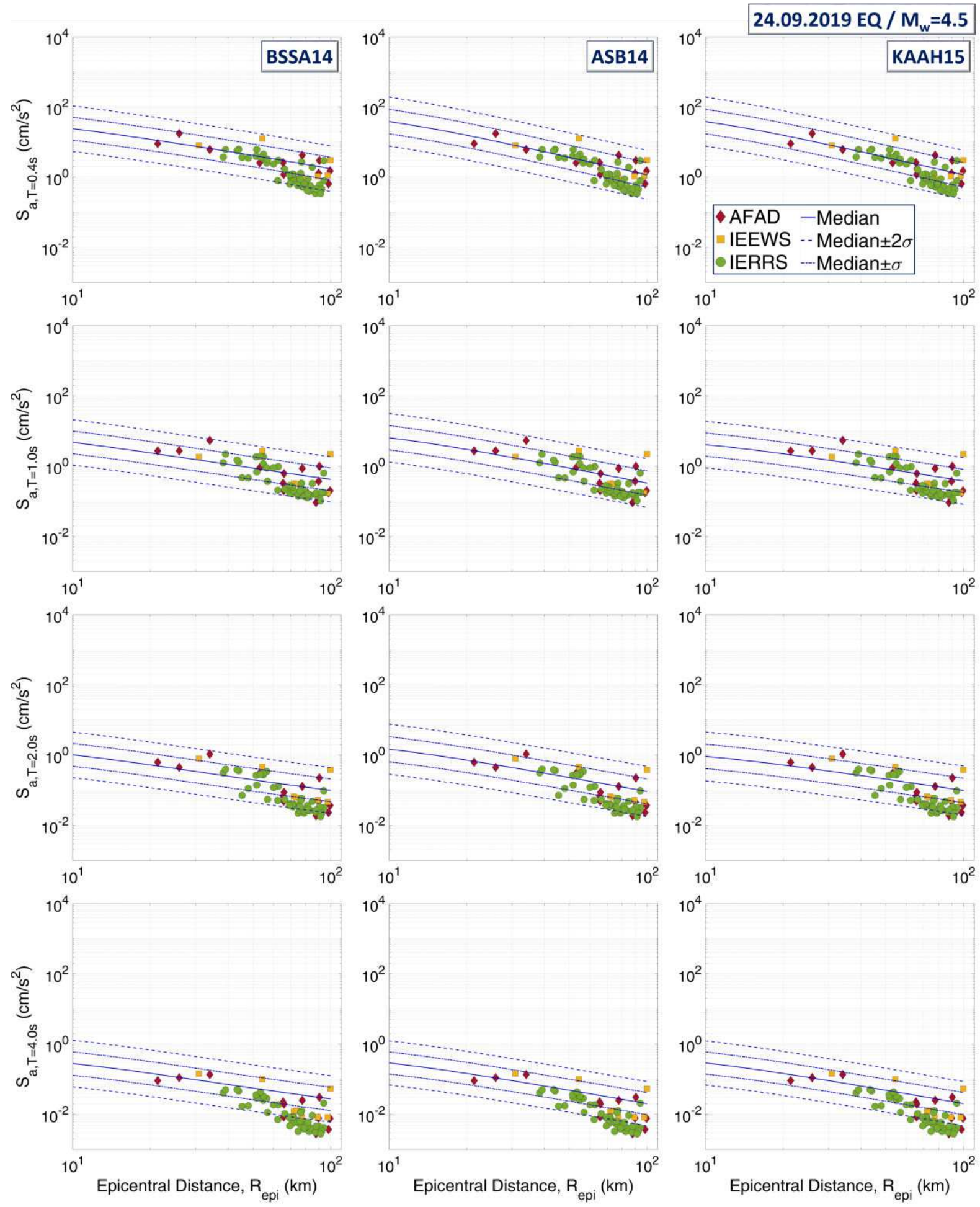

Fig. 11 Variation of SAs for four different periods ( $\mathrm{T}=0.4 ; 1.0 ; 2.0$ and $4.0 \mathrm{~s}$ ) with epicentral distance for the $\mathrm{M}_{\mathrm{w}} 4.5$ earthquake. 
26.09.2019 EQ / $\mathrm{M}_{\mathrm{w}}=5.7$
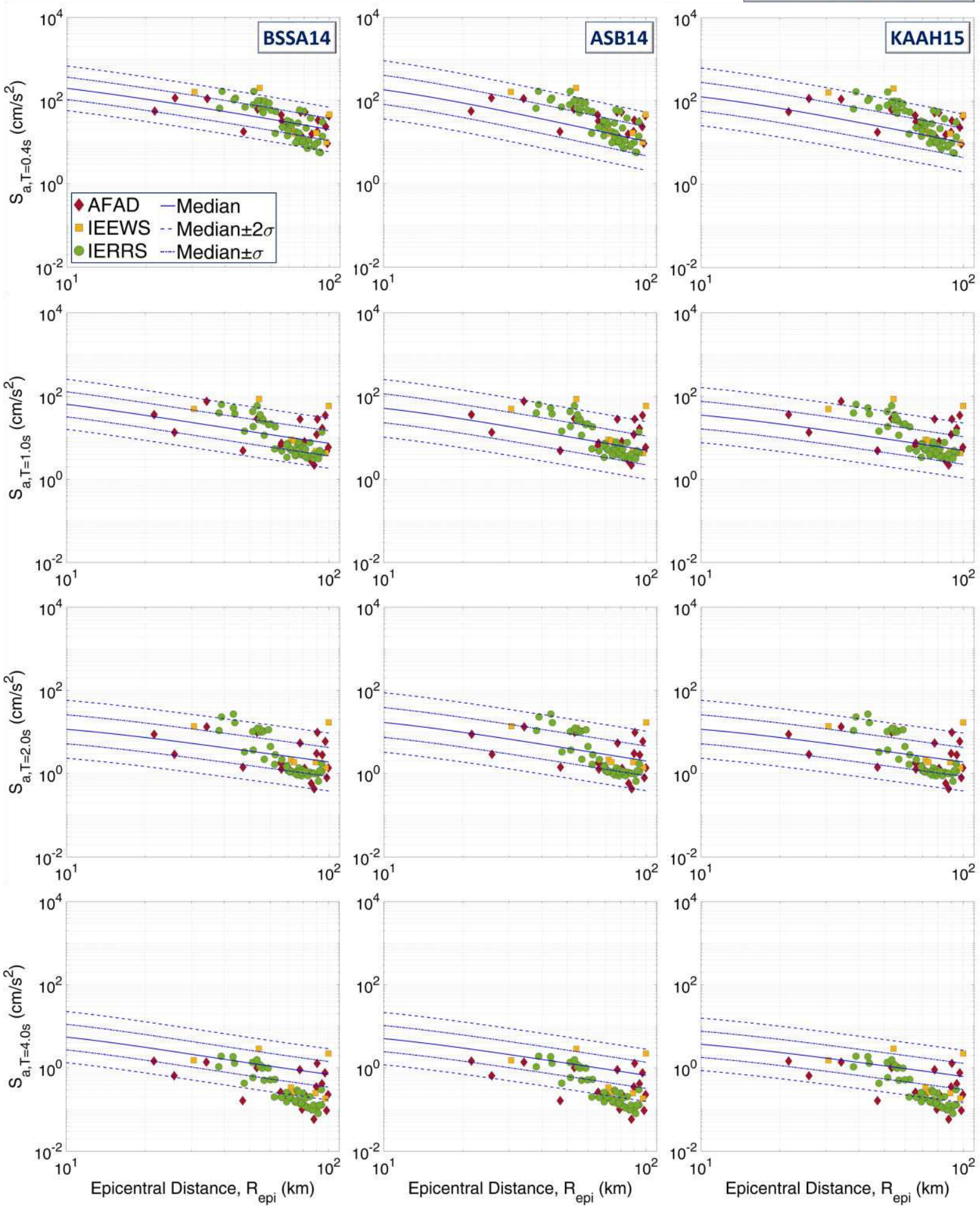

Fig. 12 Variation of SAs for four different periods ( $\mathrm{T}=0.4 ; 1.0 ; 2.0$ and $4.0 \mathrm{~s}$ ) with epicentral distance for the $\mathrm{M}_{\mathrm{w}} 4.5$ earthquake. 


\section{Anelastic Attenuation Parameter}

The frequency-dependent anelastic attenuation, $Q_{s}(f)$, of these events is analysed by observing the spectral decays at selected central frequencies by using acceleration Fourier amplitude spectra of S-waves (Anderson and Quaas 1988) to estimate Qs in the form of,

$$
Q_{s}(f)=Q_{0} \times f^{n}
$$

where $\mathrm{Q}_{0}$ is the value of $\mathrm{Q}_{\mathrm{s}}$ at $1 \mathrm{~Hz}$ and $\mathrm{n}$ is the frequency parameter. As it is defined, $\mathrm{Q}_{s}$ varies within the crust in regard to inelasticity or scattering, or both at the same time and it is inversely proportional to attenuation. To estimate frequency-dependent $\mathrm{Q}_{\mathrm{S}}(\mathrm{f})$, at first, it is needed to calculate spectral amplitudes at selected central frequencies. For our case, eleven central frequencies are selected. We make use of all the recordings with adequate bandwidths, covering the selected range (Table 5) to calculate the spectral amplitudes. They are calculated by taking the mean of the amplitudes in each predefined frequency bin. The overall considered frequency range is between $0.5 \mathrm{~Hz}$ and $21 \mathrm{~Hz}$. Selected central frequencies and their corresponding \pm ranges that form the bins are presented in .

To decrease the possible bias of site effects, we utilized only the vertical components of the recordings and those having very high signal-to-noise ratios. The calculated mean amplitude values for the given bins are denoted as $U(f, r)$. These values are conventionally corrected by a geometrical spreading model, $G\left(R_{h y p}\right)$, expressed in the form of $R_{h y p}^{-\gamma}$. In our study, the $\gamma$ exponent is selected as 1, following the approaches of Frankel et al. (1990) and Horasan and Boztepe-Güney (2004). Once the $U(f, r)$ values are divided by the geometrical spreading model, we take their logarithms and plot them against hypocentral distance. The process can be described as,

$$
\left(R_{\text {hyp }}\right)=\ln \left[\frac{U(f, r)}{G\left(R_{\text {hyp }}\right)}\right]=a-b \times R_{\text {hyp }}
$$

where $a$ is the source dependent parameter and $b$ is the slope. $a$ and $b$ values can be written as,

$$
\begin{gathered}
a=\log S \\
b=\frac{\pi f}{Q_{s} \beta}
\end{gathered}
$$

where $\beta$ is the average $S$-wave velocity. $Q_{S}$ is calculated from the slope of the first-degree polynomial fitted over the $u\left(R_{\text {hyp }}\right)$ data points distributed against hypocentral distance. The regression analysis in equation 15 and the following $Q_{s}$ estimation are repeated for each central frequency. Therefore, we obtain a $Q_{s}$ value for each central frequency. 
We study $Q_{s}$ for two cases. In the first case, we consider only the stations located within Istanbul, which are indicated in Figure 13. This allows us to study the $\mathrm{Q}_{\mathrm{s}}$ along a certain crustal path. It should be noted that removing any of the data from this specific set of stations defined for Istanbul does not affect the results in a significant way - which shows a consistency along this path. However, it was also observed that when data from the outer region were added, the results tend to differ noticeably. The latter observation is covered by the second case, containing the rest of the recordings in the analysis. Thus, the result of the analysis for the second case allows us to provide a general frequency-dependent $Q_{s}$ model valid for the northeast Marmara.

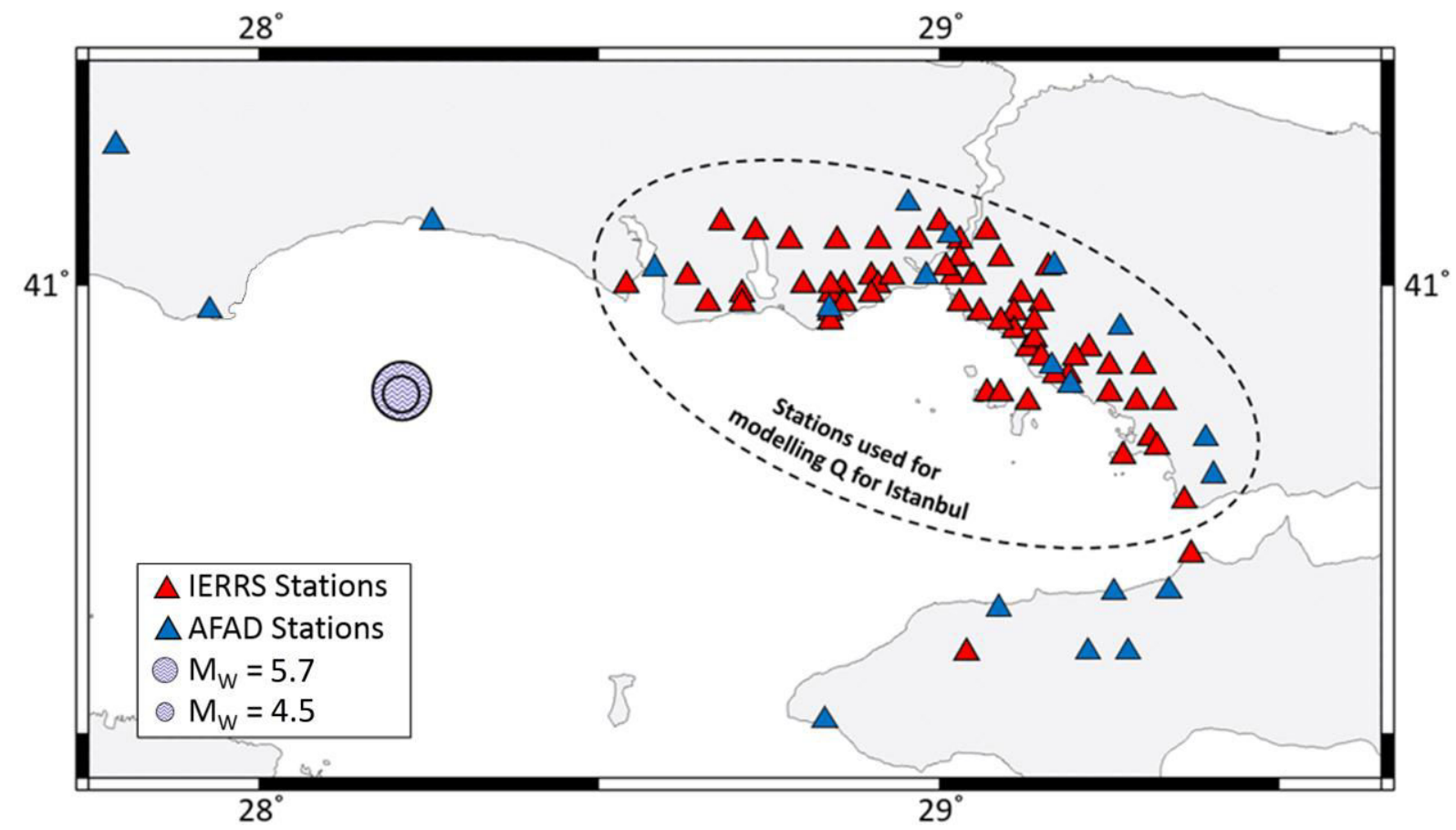

Fig. 13 Stations used for modelling Q for Istanbul.

Overall results indicate that the $Q_{s}$ models prepared in the first case are very similar, as well as the models in the second case. As the sources and considered stations almost overlap, path properties are expected to match, just as we can observe in our results (Table 5, Fig. 14). The Qs values show minor differences between the models for Istanbul and the ones for the northeast Marmara at low frequencies. However, at higher frequencies, the models for the northeast Marmara have lower values. These models show a very good agreement with the models prepared for the Marmara region in Horasan et al. (1998) and in Horasan and Boztepe-Güney (2004), which are also added to Table 5 and to Figure 14. 
Table $5 Q_{s}$ estimations at selected frequencies and frequency-dependent $Q_{s}$ models.

\begin{tabular}{|c|c|c|c|c|c|}
\hline \multirow[b]{2}{*}{$\begin{array}{r}\text { Central } \\
\text { frequencies } \\
(\mathrm{Hz})\end{array}$} & \multirow[b]{2}{*}{$\begin{array}{l}\text { Frequeny } \\
\text { range }\end{array}$} & \multicolumn{2}{|c|}{ Istanbul } & \multicolumn{2}{|c|}{ Northeast Marmara } \\
\hline & & $M_{W}=4.5$ & $M_{W}=5.7$ & $M_{W}=4.5$ & $M_{W}=5.7$ \\
\hline 1 & \pm 0.5 & 41 & 39 & 55 & 56 \\
\hline 1.5 & \pm 0.5 & 65 & 61 & 84 & 81 \\
\hline 2 & \pm 0.5 & 88 & 81 & 109 & 101 \\
\hline 2.5 & \pm 0.5 & 112 & 103 & 135 & 120 \\
\hline 3 & \pm 0.5 & 141 & 131 & 166 & 136 \\
\hline 4 & \pm 2 & 217 & 201 & 243 & 185 \\
\hline 6 & \pm 2 & 322 & 305 & 329 & 313 \\
\hline 9 & \pm 3 & 414 & 478 & 383 & 508 \\
\hline 12 & \pm 3 & 679 & 850 & 588 & 614 \\
\hline 15 & \pm 3 & 972 & 1183 & 797 & 697 \\
\hline 18 & \pm 3 & 1140 & 1269 & 930 & 949 \\
\hline \multicolumn{2}{|c|}{ This study } & $34 \pm 5^{1.22 \pm 0.06}$ & $33 \pm 7 f^{1.28 \pm 0.08}$ & $52 \pm 7 f^{1 \pm 0.05}$ & $51 \pm 6 f^{1 \pm 0.05}$ \\
\hline \multicolumn{2}{|c|}{$\begin{array}{c}\text { Horasan et al. (1998) - Sea } \\
\text { of Marmara }\end{array}$} & \multicolumn{4}{|c|}{$50 \pm 1.7 \mathrm{f}^{1.09 \pm 0.05}$} \\
\hline \multicolumn{2}{|c|}{$\begin{array}{c}\text { Horasan and Boztepe- } \\
\text { Güney (2004) - Sea of } \\
\text { Marmara }\end{array}$} & \multicolumn{4}{|c|}{$40 \pm 5 \mathrm{f}^{1.03 \pm 0.06}$} \\
\hline
\end{tabular}

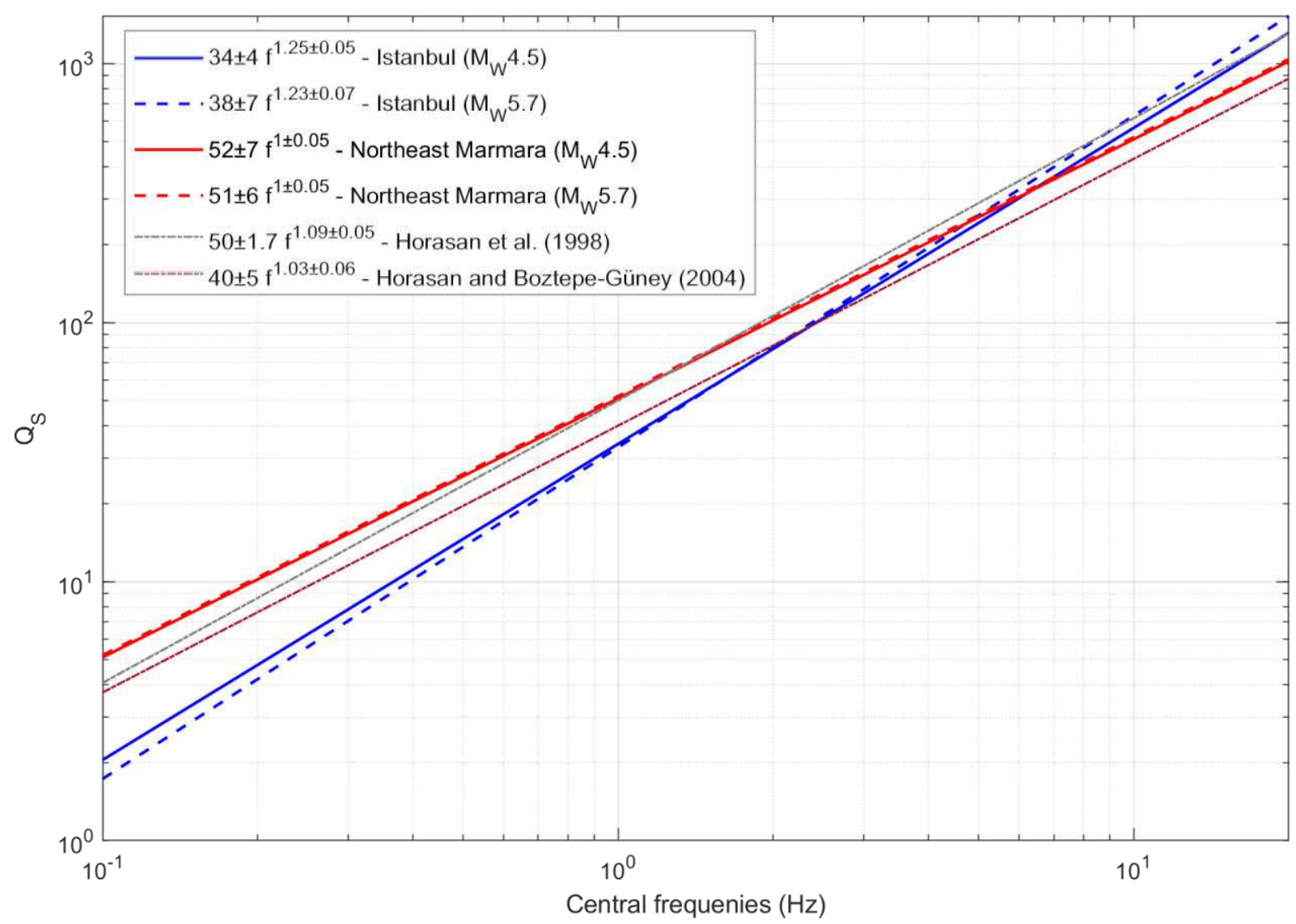

Fig. 14 Frequency-dependent $Q_{s}$ models prepared in this study, compared with past studies. 


\section{Conclusion}

In this study, we examined the seismological and engineering parameters of two earthquakes that occurred at an exceptional location in the Marmara Sea, where not many events were reported in the recent past. We had the opportunity to use the majority of the existing recordings associated with these events that allowed us to study several aspects of these events. The overall conclusions can be summarized as follows:

- Estimated source parameters of the $\mathrm{M}_{\mathrm{W}} 4.5$ event are in reasonable agreement with those from global models for moderate magnitude, strike-slip events. However, the area and the stress drop of the $M_{\mathrm{w}} 5.7$ event are exceptionally high considering the known nature of NAF's central Marmara segment.

- The time difference between hand-picked P-wave and S-wave onsets is modelled as $0.118 \times R_{\text {hyp }}$. It is correlated only with distance, as the regressed model intersects almost at zero. This model is slightly different than the globally used relation of $R_{\text {hyp }} / 8$ (Ancheta et al. 2013; Kishida et al. 2016).

- The path components of significant duration and S-wave duration models have very similar values. They also match with the global models. The 5\%-75\% significant duration models are very close to the S-wave duration model. In addition to this, the 5\%-75\% significant duration estimates for the vertical component have a clear linear trend with hypocentral distance, yielding $2.90( \pm 1.85)+0.13( \pm 0.03) \times R_{\text {hyp }}$ and $2.74( \pm 2.08)+$ $0.12( \pm 0.03) \times R_{\text {hyp }}$ for $\mathrm{M}_{\mathrm{W}} 4.5$ and $\mathrm{M}_{\mathrm{w}} 5.7$ events, respectively.

- Maxima of peak ground motion parameters and SAs are registered at closer stations, which are located on the north Coast of Marmara Sea, on softer soils.

- The PGAs, PGVs and SAs of the $\mathrm{M}_{\mathrm{w}} 5.7$ earthquake are more scattered when compared to those of the smaller event. As a result, the data spread between median $\pm 2 \sigma$ lines of the three GMPEs employed.

- Our results suggest that beyond $60 \mathrm{~km}$ from the earthquake source zone the peak and spectral ground motion values start to attenuate distinctively faster. This observation needs to be explored further for underlying reasons, which could be related to regional geometrical spreading or intrinsic attenuation properties. Investigation of a larger data set that includes earthquakes originating from the same and other NAF segments in the Marmara Sea for that matter will be the next step.

- We analysed the anelastic attenuation for the northeast of Marmara, by considering two cases: first, the case in which only the stations within Istanbul are considered; second, the case in which all the available stations in northeast Marmara is considered. We 
observed that a similar attenuation exists at low frequencies, in all models. Besides that, discrepancies emerge at high frequencies. In the first case, anelastic attenuation was

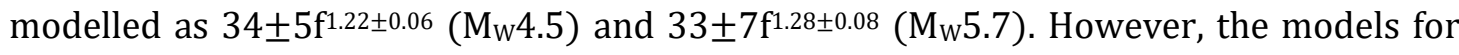
northeast Marmara resulted as $52 \pm 7 \mathrm{f}^{ \pm \pm 0.05}\left(\mathrm{M}_{\mathrm{W}} 4.5\right)$ and $51 \pm 6 \mathrm{f} 1 \pm 0.05\left(\mathrm{M}_{\mathrm{W}} 5.7\right)$. Overall, they show a good agreement with the past models prepared for this region.

\section{Acknowledgments}

We are indebted to Erdal Şafak for providing us useful feedback on this work. All contributions are gratefully acknowledged.

\section{Declarations}

\section{Funding}

This work has been partially supported by UKRI-GCRF in the framework of project "Tomorrow's Cities".

\section{Conflict of interest}

The authors declare that they have no conflict of interest.

\section{Availability of data and material}

The study is based on the data from the Istanbul Earthquake Rapid Response and Early Warning System operated by the Department of Earthquake Engineering of Boğaziçi University's Kandilli Observatory and Earthquake Research Institute and from AFAD.

\section{Code availability}

Not applicable

\section{References}

Aki K (1972) Earthquake mechanism, Tectonophysics, 13 (1-4), 423-446.

Akkar S, Sandıkkaya MA, Bommer JJ (2014) Empirical ground-motion models for point- and extendedsource crustal earthquake scenarios in Europe and the Middle East, Bulletin of Earthquake Eng 12: 359. https://doi.org/10.1007/s10518-013-9461-4.

Allmann BP, Shearer PM 2009. Global variations of stress drop for moderate to large earthquakes, Journal of Geophysical Research: Solid Earth, 114(B1).

Ambraseys NN, Bommer JJ (1991) The attenuation of ground accelerations in Europe, Earthquake Engineering \& Structural Dynamics, 20, 1179-1202

Ancheta TD, Darragh RB, Stewart JP, Seyhan E, Silva WJ, Chiou B-SJ, Wooddell KE, Graves RW, Kottke AR, Boore DM, Kishida T, Donahue JL (2013) PEER NGA-West2 database, PEER Report No. 2013/03, Pacific Earthquake Engineering Research Center, University of California, Berkeley, CA.

Anderson JG, Quaas R (1988) The Mexico earthquake of September 19, 1985-Effect of magnitude on the character of strong ground motion: An example from the Guerrero, Mexico strong motion network, Earthquake Spectra, 4(3), 635-646.

Andrews DJ (1986) Objective determination of source parameters and similarity of earthquakes of different size, Earthquake source mechanics, 37, 259-267.

Arias A (1970)A measure of earthquake intensity in seismic design of nuclear power plants, Massachusetts Inst. of Tech., Cambridge. Univ. of Chile, Santiago de Chile. 
Atkinson GM (1993) Earthquake source spectra in eastern North America, Bull Seismol. Soc. Am. 83:17781798.

Beresnev IA (2002) Source parameters observable from the corner frequency of earthquake spectra, Bulletin of the Seismological Society of America, 92(5), 2047-2048.

Boatwright J, Choy GL (1992) Acceleration source spectra anticipated for large earthquakes in northeastern North America, Bulletin of the Seismological Society of America, 82(2), 660-682.

Bommer JJ, Stafford PJ, Alarcón JE (2009) Empirical equations for the prediction of the significant, bracketed, and uniform duration of earthquake ground motion, Bulletin of the Seismological Society of America, 99(6), 3217-3233.

Boore DM (1983) Stochastic simulation of high-frequency ground motions based on seismological models of the radiated spectra, Bulletin of the Seismological Society of America, 73(6A), 1865-1894.

Boore DM, Stewart JP, Seyhan E, Atkinson GM (2014) NGA-West2 Equations for Predicting PGA, PGV, and 5\% Damped PSA for Shallow Crustal Earthquakes, Earthquake Spectra: August 2014, Vol. 30, No. 3, pp. 1057-1085. https://doi.org/10.1193/070113EQS184M.

Brune JN (1970) Tectonic stress and the spectra of seismic shear waves from earthquakes, Journal of Geophysical Research, 75(26), 4997-5009.

Denolle MA, Shearer PM (2016) New perspectives on self-similarity for shallow thrust earthquakes, Journal of Geophysical Research: Solid Earth, 121(9), 6533-6565.

EMSC-CSEM, European-Mediterranean Seismological Centre Earthquake Catalog, last accessed January 11, 2021, Available at http://www.emsc-csem.org/Earthquake/?filter=yes.

Eshelby JD (1957) The determination of the elastic field of an ellipsoidal inclusion, and related problems, Proceedings of the royal society of London. Series A. Mathematical and physical sciences, 241(1226), 376-396.

Eyidogan H, Sevilgen V (2019) Strong earthquake strikes near the Marmara Fault, damaging 77 buildings and frightening Istanbul residents, Temblor. http://doi.org/10.32858/temblor.047.

Frankel A, McGarr A, Bicknell J, Mori J, Seeber L, Cranswick E (1990) Attenuation of high-frequency shear waves in the crust: Measurements from New York state, South Africa, and southern California. Journal of Geophysical Research: Solid Earth, 95(B11), 17441-17457.

Ghofrani H, Atkinson GM (2015) Duration of the 2011 Tohoku earthquake ground motions. Journal of Seismology, 19(1), 9-25.

Hanks TC, Kanamori H (1979) A moment magnitude scale, J. Geophys. Res., 84,2348-2350.

Hanks TC, McGuire RK (1981) The character of high-frequency strong ground motion, Bulletin of the Seismological Society of America, 71(6), 2071-2095.

Horasan G, Kaslılar-Ozcan A, Boztepe-Guney A, Turkell, N (1998) S-wave attenuation in the Marmara region, northwestern Turkey, Geophys. Res. Lett, 25(14), 2733-2736.

Horasan, G, Boztepe-Güney, A (2004) S-wave attenuation in the Sea of Marmara, Turkey, Physics of the Earth and Planetary Interiors, 142(3-4), 215-224.

Istanbul Metropolitan Municipality (2007) Istanbul \& Earthquake, European Side South Microzonation Project (online), last accessed October 10, 2019, available at http://www.ibb.gov.tr/trTR/SubSites/EarthquakeSiteEn/Pages/MicrozonationProjectEuropeanSideSouth.aspx.

Istanbul Metropolitan Municipality (2009) Istanbul \& Earthquake, Anatolian Side Microzonation Project (online), last accessed October 10, 2019, available at http://www.ibb.gov.tr/trTR/SubSites/EarthquakeSiteEn/Pages/AntolianSideMicrozonationProject.aspx.

Kale Ö, Akkar S, Ansari A, Hamzehloo H (2015) A Ground-Motion Predictive Model for Iran and Turkey for Horizontal PGA, PGV, and 5\% Damped Response Spectrum: Investigation of Possible Regional Effects. Bulletin of the Seismological Society of America, 105 (2A): 963-980. https://doi.org/10.1785/0120140134.

Karabulut H, Güvercin SE, Eskiköy F, Konca AÖ, Ergintav S (2021) The moderate size 2019 September M w 5.8 Silivri earthquake unveils the complexity of the Main Marmara Fault shear zone, Geophysical Journal International, 224(1), 377-388. https://doi.org/10.1093/gji/ggaa469.

Keilis-Borok VI, Monin AS (1959) Magnetoelastic Waves and the Boundary of the Earth's Core, Izv. Akad. Nauk SSSR, Ser. Geofiz, (11), 1529-1541.

Kempton JJ, Stewart JP (2006) Prediction equations for significant duration of earthquake ground motions considering site and near-source effects, Earthquake Spectra, 22: 985-1013. 
Kishida T, Ktenidou OJ, Darragh RB, Walter S (2016) Semi-automated procedure for windowing time series and computing Fourier amplitude spectra (FAS) for the NGA-West2 database.

KOERI-RETMC (2019a) 24 September 2019 off the coast of Silivri - İstanbul (Marmara Sea) Earthquake, press release, (in Turkish).

KOERI-RETMC (2019b) 26 September 2019 off the coast of Silivri - İstanbul (Marmara Sea) Earthquake, press release, (in Turkish).

KOERI-RETMC Earthquake Catalog Search System (2020) Last accessed December 06, 2020, available at http://www.koeri.boun.edu.tr/sismo/zeqdb/indexeng.asp

kyhdata.deprem.gov.tr (2020) Republic of Turkey Prime Ministry Disaster \& Emergency Management Authority (AFAD) Official Website, last accessed October 27, 2020, available at http://kyhdata.deprem.gov.tr.

MTA, General Directorate of Mineral Research and Exploration (2004) 1/500,000 scale geological maps of Turkey, https://www.mta.gov.tr/v3.0/hizmetler /500cd.

Raoof M, Herrmann RB, Malagnini L (1999) Attenuation and excitation of three-component ground motion in southern California, Bulletin of the Seismological Society of America, 89(4), 888-902.

Regional Earthquake-Tsunami Monitoring Center, Kandilli Observatory and Research Institute, Boğaziçi University, Turkey (2018) Personal communication.

Sarma SK (1970) Energy flux of strong earthquakes, Tectonophysics, 11:159-173.

Thingbaijam KKS, Mai PM, Goda K (2017) New empirical earthquake source-scaling laws, Bulletin of the Seismological Society of America, 107(5), 2225-2246.

USGS, United States Geological Survey, America. Last accessed January 11, 2021, available at https://earthquake.usgs.gov/.

Wells DL, Coppersmith KJ (1994) New empirical relationships among magnitude, rupture length, rupture width, rupture area, and surface displacement, Bulletin of the seismological Society of America, 84(4), 974-1002. 